\title{
OXIDATIVE HEMOLYSIS AND PRECIPITATION OF HEMOGLOBIN. II. ROLE OF THIOLS IN OXIDANT DRUG ACTION *
}

\author{
By DAVID W. ALLEN ANd JAMES H. JANDL \\ (From the Thorndike Memorial Laboratory and Second and Fourth (Harvard) Medical \\ Services, Boston City Hospital, and the Department of Medicine, Harvard \\ Medical School, Boston, Mass.)
}

(Submitted for publication August 15, 1960; accepted October 27, 1960)

In a preceding report (1) it was shown that those redox compounds that cause Heinz body anemias in vivo produce a sequence of changes in vitro in solutions of crystalline hemoglobin culminating in the precipitation of hemoglobin as spherical granules. These granules appear to be identical with Heinz bodies. The sequence of changes produced in hemoglobin by these compounds includes: 1) the formation of methemoglobin, 2) an increase in electrophoretic and chromatographic mobility, 3 ) the appearance of irreversible hemochromes such as sulfhemoglobin and 4) frank precipitation. It was found that similar changes in hemoglobin were produced rapidly by "simple" oxidants such as ferricyanide and slowly by prolonged incubation of hemoglobin alone under oxygen. Compounds that cause Heinz body anemias apparently are converted under oxygen into redox intermediates or free radicals which catalyze the oxidative breakdown of hemoglobin, a process which proceeds spontaneously only slowly in vitro and presumably still more slowly during cellular aging in vivo.

There are many reasons to suspect the involvement of sulfhydryl (thiol) groups in the processes described above. Such groups are readily oxidized under physiologic conditions and are involved in maintaining the integrity of the red cell (2) and the physiologic activity of hemoglobin (3). The studies of Beutler and his co-workers $(4,5)$ have established an association between intracellular reduced glutathione $(\mathrm{GSH})$ levels and the susceptibility in vitro and in vivo of red cells to injury by oxidant drugs. Based on studies of "choleglobin" formation in the presence of ascorbic acid, Mills (6) has advanced the hypothesis that GSH protects hemoglobin from oxidative

* This investigation was supported in part by Grant RG3507 (C8) from the National Institutes of Health, Bethesda. Md. breakdown by acting as a hydrogen donor in the peroxidative destruction of hydrogen peroxide. The necessity for regenerating GSH in such a mechanism would conceivably explain the hypersusceptibility to the action of oxidant compounds of red cells deficient in glucose or in glucose-6phosphate dehydrogenase (7), since in the red cell, oxidative glycolysis via the pentose phosphate pathway (8), possibly supplemented by anaerobic glycolysis (9), provides the energy for reducing glutathione. On the other hand, there are certain differences between phenylhydrazine-like compounds and hydrogen peroxide in their action on hemoglobin (1). Phenylhydrazine and related compounds appear to destroy hemoglobin through the formation of a series of oxidant derivatives which may resemble, but are not identical with, hydrogen peroxide.

The following studies were conducted in order to explore the participation of thiol groups in the oxidative destruction of hemoglobin.

\section{METHODS}

Preparation of reagents. As described previously (1) buffered solutions of crystalline human hemoglobin were prepared by the method of Drabkin (10), and phenylhydrazine and related compounds were dissolved in isotonic $(0.12 \mathrm{M})$ phosphate buffer, $\mathrm{pH}$ 7.4. Unless otherwise stated, glutathione, ${ }^{1}$ an acid, was dissolved immediately before use in physiologic saline [since its reduced form is more stable at a low $\mathrm{pH}(11)]$ and was added slowly to buffered solutions of hemoglobin in amounts that did not affect the final $\mathrm{pH}$ of the solution. The sulfhydryl-binding compound, sodium $p$-chloromercuribenzoate $^{2}$ (PCMB), is a base (probably existing as sodium $p$-hydroxymercuribenzoate) that is very poorly soluble at a physiologic $\mathrm{pH}$; therefore it too was dissolved in unbuffered saline as a concentrate, which was then added slowly to buffered solutions of hemoglobin.

General procedures. Methemoglobin and so-called sulfhemoglobin were measured by the Evelyn-Malloy

${ }^{1}$ Schwarz Bioresearch, Inc., Mount Vernon, N. Y.

2 Sigma Chemical Co., St. Louis, Mo. 
procedure (12) as described elsewhere (1). Heinz bodies in red cells and granules of precipitated hemoglobin were stained by suspension in isotonic crystal violet. The weights of hemoglobin precipitates were determined with the aid of high speed centrifugation (1). Filter paper electrophoresis at $\mathrm{pH} 8.6$ and ion-exchange resin column chromatography at $\mathrm{pH} 7.1$ were carried out as reported earlier $(1,13)$.

Studies involving radioactive glutathione. To explore the possibility that, during the oxidation of GSH in the presence of hemoglobin, mixed disulfides may form involving GSH and the cysteinyl residues of globin, studies were made of the binding to hemoglobin of GSH labeled with either $\mathrm{S}^{35}$ or $\mathrm{C}^{14} .^{1}$ Flasks containing solutions of hemoglobin were incubated at $0^{\circ}$ or $37^{\circ} \mathrm{C}$ with labeled glutathione. To some of these flasks phenylhydrazine was added at the onset of the 2 hour incubation period, after which all flasks were chilled in an ice bath. As a control of the amount of labeled glutathione trapped by precipitated hemoglobin, labeled glutathione was added at the conclusion of incubation, rather than at the beginning, in some of the phenylhydrazine-containing flasks. After chilling of the specimens, quadruplicate $2 \mathrm{ml} \mathrm{sam-}$ ples were precipitated with $6 \mathrm{ml}$ of 10 per cent trichloroacetic acid (TCA) and the precipitate was washed twice with 5 per cent TCA, once with absolute ethyl alcohol, and once with ether before drying. To ascertain whether any GSH remaining with the precipitate was attached by disulfide linkage, the ability of thioglycollic acid to detach this GSH was determined. Accordingly, the dried precipitates in one pair of each quadruplicate set of tubes were dissolved in 20 per cent thioglycollic acid and those of the other pair in 40 per cent glycollic acid. ${ }^{3}$ These solutions were allowed to stand at room temperature overnight under nitrogen, after which the protein was reprecipitated by TCA, washed, and dried as described above. The dried precipitates were weighed, dissolved in $0.1 \mathrm{~N} \mathrm{NaOH}$, and $0.1 \mathrm{ml}$ samples were spread and dried on stainless steel planchets for measurement of radioactivity.

In flasks to which phenylhydrazine had been added, a portion of the contents was studied for the radioactivity of the hemoglobin precipitated by the phenylhydrazine. This precipitate was secured by cold centrifugation at $105,000 \mathrm{G}$, was dried under vacuum, dissolved with $0.1 \mathrm{~N}$ $\mathrm{NaOH}$, and spread on planchets as described above.

Radioactivity was measured with a windowless flow counter. To obviate variations in self-absorption, all specimens, including standards, were adjusted to a uniform concentration of solids prior to sampling.

Autoradiographs of radioactive glutathione bound to hemoglobin were obtained by exposing $\mathrm{X}$-ray films to filter paper electrophoretograms of the unprecipitated hemoglobin solutions dialyzed free of unbound glutathione. The electrophoretic and autoradiographic spots were quantitated with a photoelectric densitometer.

3 This concentration of glycollic acid, used as the nonthiollic control, was selected on the basis of the relative dissociation constants of these two compounds.
Determination of glutathione. Reduced glutathione was measured by the nitroprusside method of Grunert and Phillips (14) as modified by Beutler (15). When glutathione was present in hemoglobin solutions, the hemolysis step was omitted from the procedure, the deionized water being replaced by additional 3 per cent metaphosphoric acid, saturated with sodium chloride. A standard curve was performed with each determination, using glutathione freshly dissolved in 1.5 per cent metaphosphoric acid. Such a preparation showed negligible increase in reduced glutathione after reduction at the mercury cathode (16) and gave 90 per cent of its theoretical mercury-combining groups in $0.05 \mathrm{M}$ borax, $0.1 \mathrm{M}$ potassium chloride, when titrated amperometrically with $1 \mathrm{mM}$ mercuric chloride using the rotating platinum electrode (17).

Total glutathione was determined on a $10 \mathrm{ml}$ aliquot of the metaphosphoric acid filtrate reduced over a mercury cathode in a $50 \mathrm{ml}$ beaker by $40 \mathrm{ma}$ of current, as described by Dohan and Woodward (16); 95 per cent reduction occurred by the end of 20 minutes, and reduction was routinely carried out 10 minutes longer.

Determination of mercury-combining sites in hemoglobin. The hemoglobin mercury-combining sites were titrated amperometrically by a modification of the method of Kolthoff, Stricks and Morren (17). A mercurycoated platinum wire electrode was used $(0.5 \mathrm{~cm}$ long, rotated by a synchronous motor). This indicator electrode was kept -0.1 volt versus a commercial electrode (Beckman Calomel Reference Electrode, fiber type) using a manually operated circuit.

The titration of native hemoglobin mercury-binding groups was done in $25 \mathrm{ml}$ of $0.5 \mathrm{M}$ potassium chloride,

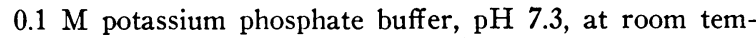
perature $\left(22^{\circ}\right.$ to $\left.27^{\circ} \mathrm{C}\right)$ in a $50 \mathrm{ml}$ beaker. Two to $4 \mathrm{ml}$ of approximately $0.1 \mathrm{mM}$ hemoglobin solution, usually as its carbon monoxide derivative, was added to the buffer through which nitrogen had been bubbled. The residual current was read, then $1 \mathrm{mM}$ mercuric chloride was added in $0.1 \mathrm{ml}$ increments, as the solution was stirred briskly, and the diffusion current read. The whole titration required less than 5 minutes. There was no increase in galvanometer reading until the mercury-binding sites had been exceeded, allowing a sharp endpoint. It was noted that after the equivalence point was reached following additions of mercuric chloride, the diffusion current tended to fall slowly with time, probably as a result of much slower binding of mercury by other sulfhydryl groups. However, this phenomenon did not interfere with the determination of primary mercury-combining sites. The total hemoglobin mercury-binding groups were titrated, using denatured hemoglobin; the conditions were the same as in the titration of native hemoglobin except that the titration fluid was $8 \mathrm{M}$ in urea. As a preliminary test of the electrode, prior to the addition of hemoglobin, $1 \mathrm{mM}$ mercuric chloride was added to the titration fluid in $0.1 \mathrm{ml}$ increments, the beaker contents stirred mechanically under nitrogen, and the galvanometer reading recorded until $0.8 \mathrm{ml}$ (an excess of mercury) had been added. If the galvanometer failed to 
TABLE I

Oxygen requirement for oxidation of reduced glutathione (GSH) (40 mg \%) by phenylhydrazine (0.1\%) and acetylphenylhydrazine $(0.5 \%)$ in isotonic phosphate buffer, $p H 7.4$, at $37^{\circ} \mathrm{C}$

\begin{tabular}{|c|c|c|}
\hline $\begin{array}{l}\text { Gas and additions during preincub. } \\
(3 \mathrm{hrs})\end{array}$ & $\begin{array}{l}\text { Gas and additions during incub. } \\
(0.5 \mathrm{hr})\end{array}$ & $\begin{array}{l}\% \text { GSH } \\
\text { after incub. }\end{array}$ \\
\hline $\begin{array}{c}\mathrm{N}_{2} \\
\mathrm{O}_{2} \\
\mathrm{~N}_{2}+\text { acetylphenylhydrazine } \\
\mathrm{O}_{2}+\text { acetylphenylhydrazine } \\
\mathrm{O}_{2}+\text { acetylphenylhydrazine } \\
\mathrm{N}_{2} \\
\mathrm{O}_{2} \\
\mathrm{~N}_{2}\end{array}$ & $\begin{array}{c}\mathrm{N}_{2}+\mathrm{GSH} \\
\mathrm{O}_{2}+\mathrm{GSH} \\
\mathrm{N}_{2}+\mathrm{GSH} \\
\mathrm{O}_{2}+\mathrm{GSH} \\
\mathrm{N}_{2}+\mathrm{GSH} \\
\mathrm{N}_{2}+\text { phenylhydrazine }+\mathrm{GSH} \\
\mathrm{O}_{2}+\text { phenylhydrazine }+\mathrm{GSH} \\
\mathrm{N}_{2}+\text { ferricyanide }+\mathrm{GSH}\end{array}$ & $\begin{array}{r}100 \\
71 \\
99 \\
21 \\
30 \\
93 \\
3 \\
0\end{array}$ \\
\hline
\end{tabular}

show a linear response to mercury, the equipment was adjusted before addition of hemoglobin. Usually the difficulty, when encountered, was corrected by cleaning and replating the platinum wire with mercury. Then $1 \mathrm{ml}$ of $0.1 \mathrm{mM}$ hemoglobin was added as its carbon monoxide derivative and the solution was allowed to stand. The diffusion current fell gradually over a 5 minute period, then remained constant so that routinely the hemoglobin was allowed to stand 20 minutes with a slight excess of mercury before completing the titration, to allow for complete binding of the mercury by the hemoglobin. The titration was completed with further $0.1 \mathrm{ml}$ increments of $1 \mathrm{mM}$ mercuric chloride. With hemoglobin dialyzed free of glutathione, values between 5 and 6 mercury-combining groups per hemoglobin molecule were generally recorded, although values as low as 4 were determined on some hemoglobin solutions seemingly titrated in an identical manner.

\section{RESULTS}

Studies on the mechanism of oxidation of glutathione

Since the sulfhydryl group of glutathione can be measured by simple and reliable photometric procedures, this thiol provides a convenient substrate for study of the mechanism of action of oxidant drugs. However, in working with glutathione its known property of being readily auto-oxidized must be considered. As auto-oxidation occurs much more rapidly at high $\mathrm{pH}$ and temperature (11) these variables were strictly controlled. Trace amounts of metal ions which catalyze the oxidation of GSH were presumably present even in resin "deionized" water and were chelated when desired by dilute ethylenediamine tetraacetate (EDTA). GSH was stable at room temperature in 1.5 per cent metaphosphoric acid in the period of 1 to 2 hours it took to analyze the solutions.
1. Oxidation of glutathione by phenylhydrazine and acetylphenylhydrazine with oxygen. Phenylhydrazine and acetylphenylhydrazine require oxygen to oxidize GSH, whereas ferricyanide does not, as can be seen in Table I. In addition, this table illustrates the effect on acetylphenylhydrazine of preincubation with oxygen. The acetylphenylhydrazine, dissolved in an oxygen-free deionized buffer containing no EDTA, was preincubated in Erlenmeyer flasks sealed with vaccine caps for 3 hours, either under nitrogen or under oxygen (room air). Acetylphenylhydrazine incubated under oxygen turned yellow, whereas that under nitrogen remained colorless. Next, the solutions of acetylphenylhydrazine were washed with nitrogen. Then glutathione, dissolved under nitrogen, was added with a syringe, and the solutions were incubated 0.5 hour longer with or without oxygen. It can be seen that acetylphenylhydrazine, if preincubated under oxygen, washed free of oxygen with nitrogen, and incubated with GSH under nitrogen, resulted in approximately the same destruction of GSH as when the oxygen was present during the incubation period as well.

Table II illustrates a similar experiment which shows that the auto-oxidation of both GSH and acetylphenylhydrazine is catalyzed by trace metal ions. Trace metal ions accelerated the oxidation of acetylphenylhydrazine by oxygen during preincubation as they did the subsequent oxidation of glutathione by the oxidized drug during incubation.

2. Hemoglobin and trace metals as catalysts for the oxidation of glutathione. The experiments illustrated in Figures 1 through 4 show the similarity between hemoglobin and trace metal ions in catalyzing the destruction of glutathione by oxi- 
dant drugs. All experiments were performed in

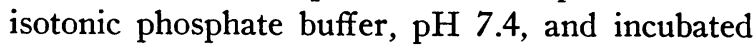
under air at $37^{\circ} \mathrm{C}$ in $50 \mathrm{ml}$ siliconized Erlenmeyer flasks in a Dubnoff metabolic shaker. In the experiments illustrated in Figures 2 and 4 trace metal ions were chelated by the presence of 0.01 per cent EDTA in all solutions used. The crystallized hemoglobin employed was present in $1 \mathrm{mM}$ concentration, the acetylphenylhydrazine in 10 $\mathrm{mM}$ concentration, and the phenylhydrazine in 2 $\mathrm{mM}$ concentration. The reaction was stopped at the end of the incubation period by immersion of the flasks in ice water, aliquots being immediately removed and precipitated with 3 vol of 3 per cent metaphosphoric acid saturated with sodium chloride for measurement of total and reduced glutathione.

In these four figures the percentage of the initial reduced glutathione remaining is plotted against time. Although selection of concentrations of phenylhydrazine and acetylphenylhydrazine was arbitrary, additional experiments with different
TABLE II

Effect of EDTA $(0.01 \%)$ on oxidation of acetylphenylhydrazine $(0.5 \%$ ) during preincubation, as shown by its subsequent oxidation of GSH (40 $\mathrm{mg} \%)$ in air in isotonic phosphate buffer, $\mathrm{pH} 7.4$, at $37^{\circ} \mathrm{C}$

\begin{tabular}{llc}
\hline \hline $\begin{array}{c}\text { Additions } \\
\text { during preincub. } \\
(3 \text { hrs })\end{array}$ & $\begin{array}{c}\text { Additions during } \\
\text { incub. } \\
(\mathbf{0 . 5} \text { hr })\end{array}$ & $\begin{array}{c}\% \text { Gluta- } \\
\text { thione } \\
\text { after } \\
\text { incub. }\end{array}$ \\
\hline $\mathbf{0}$ & EDTA +GSH & $\mathbf{1 0 0}$ \\
$\mathbf{0}$ & GSH & $\mathbf{8 0}$ \\
$\mathbf{0}$ & APH +EDTA +GSH & $\mathbf{9 4}$ \\
APH +EDTA & GSH +GSH & 65 \\
APH & EDTA +GSH & 80 \\
APH & GSH & 46 \\
& & 33 \\
& &
\end{tabular}

concentrations over different time periods confirmed the sequence of events to be described.

Figure 1 illustrates the rapid oxidation of reduced glutathione, at $37^{\circ} \mathrm{C}$ and $\mathrm{pH} 7.4$, with those trace metal ions present in resin deionized water. Glutathione alone was 40 to 50 per cent oxidized in 1 hour, and completely oxidized by 4 hours. Although acetylphenylhydrazine had negligible additional effect, phenylhydrazine increased the rate

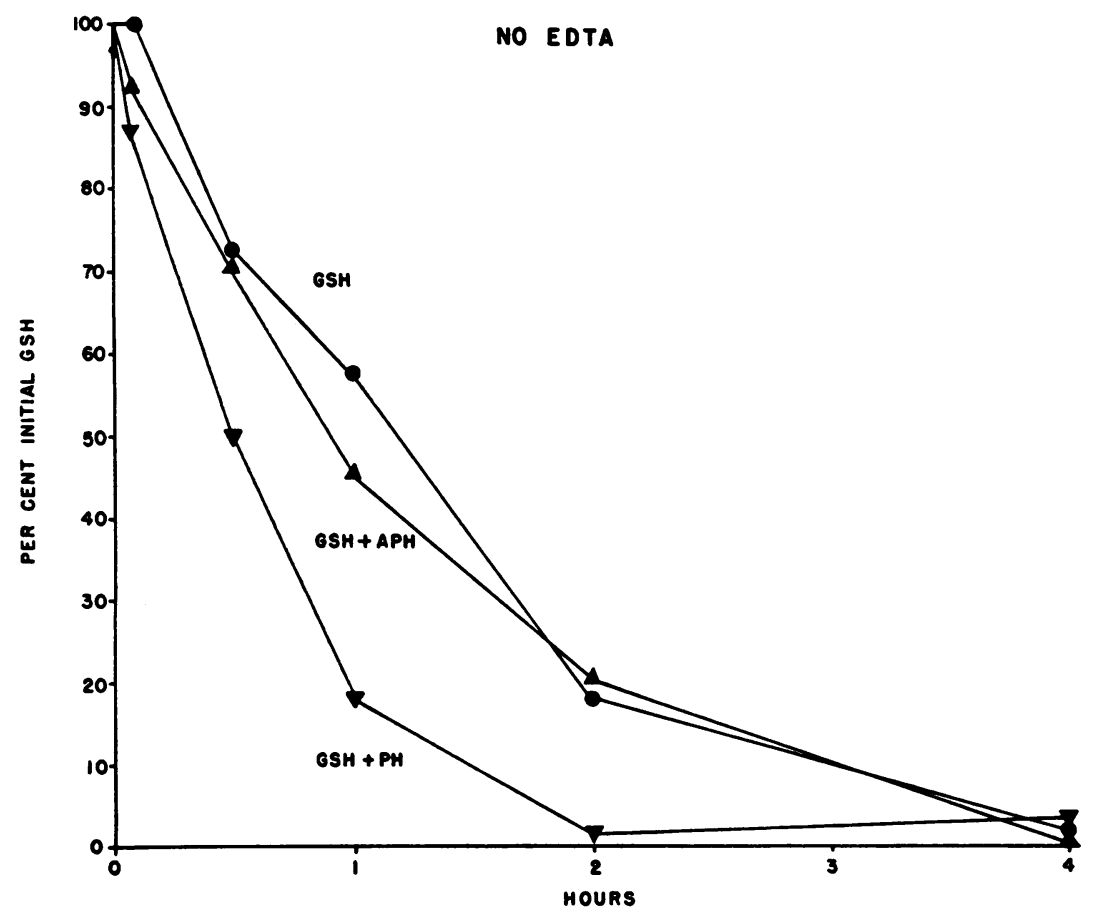

Fig. 1. The oxidation of reduced glutathione (GSH) in air, at pH 7.4, $37^{\circ} \mathrm{C}$, WITH AND WITHOUT ACETYLPHENYLHYDRAZINE AND PHENYLHYDRAZINE. The percentage of GSH remaining is plotted against the time of incubation for the control flasks $\bullet$, flasks with acetylphenylhydrazine $\boldsymbol{\Delta}$, and flasks with phenylhydrazine $\boldsymbol{\nabla}$. The solutions are made up in resin-deionized water but do not contain ethylenediamine tetraacetate (EDTA). 


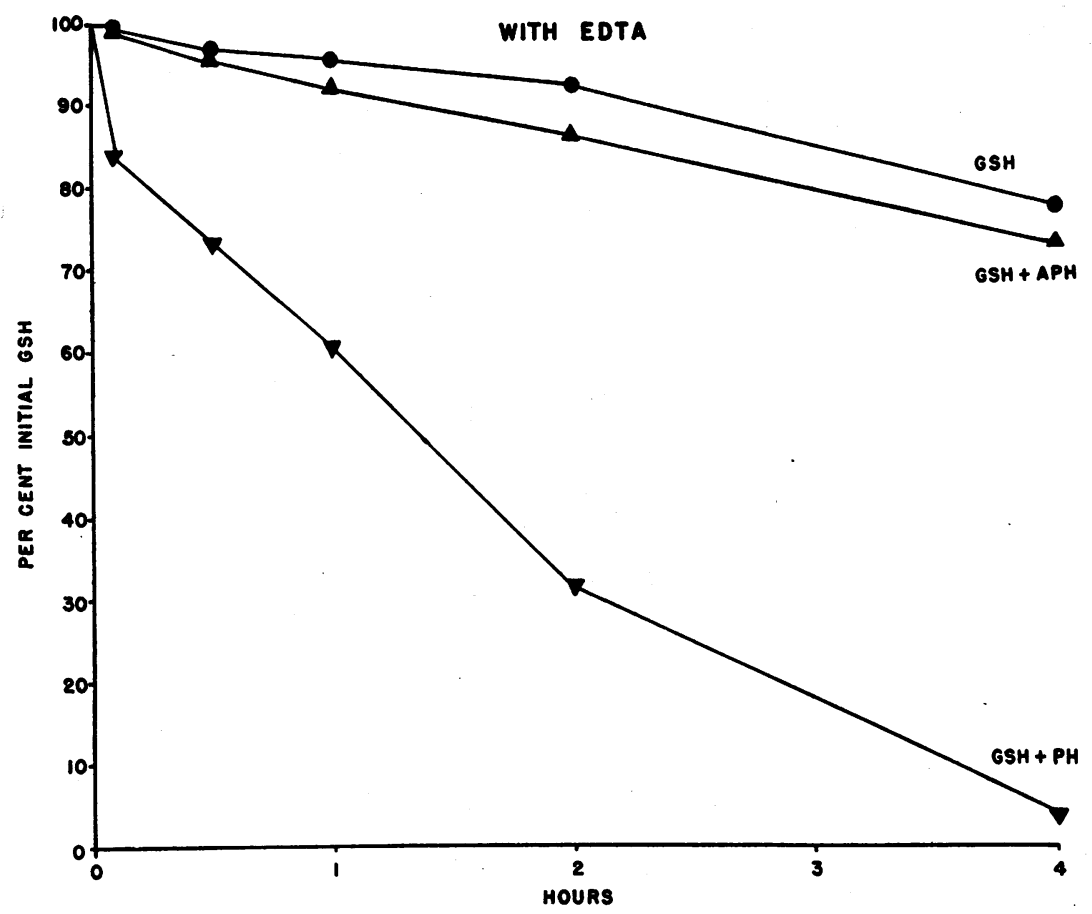

Fig. 2. The oxidation of GSH in aIr, at pH $7.4,37^{\circ} \mathrm{C}$, in the presence of 0.01 PER CENT EDTA; EITHER ALONE $\bullet$, WITH ACETYLPHENYLHYDRAZINE $\Delta$, OR WITH PHENYLhydRAzINe $\nabla$. The oxidation of GSH is slowed by chelation of trace metal ions, as can be seen by comparison with Figure 1.

of destruction, so that in its presence reduced glutathione was 50 per cent oxidized in 0.5 hour and gone by 2 hours.

Figure 2 illustrates the fact that reduced glutathione survives longer, even in the presence of acetylphenylhydrazine and phenylhydrazine, if metal ions have been chelated by EDTA. Again phenylhydrazine, but not acetylphenylhydrazine, increased the rate of destruction of GSH when compared with the control.

Figure 3 describes the time course of glutathione oxidation with hemoglobin but without EDTA. Hemoglobin alone, in the absence of EDTA, actually protected GSH (see below). The marked increase in the rate of GSH destruction with phenylhydrazine and acetylphenylhydrazine in the presence of hemoglobin, shown in Figure 3, was probably a result, therefore, of the capacity of hemoglobin to catalyze the oxidation of the drugs. Acetylphenylhydrazine, which without hemoglobin showed no demonstrable increased ability in this concentration to destroy glutathione, became markedly more active. Thus, in the presence of acetylphenylhydrazine and hemoglobin, 50 per cent oxi- dation of glutathione occurred in 0.7 hour as opposed to 1.2 hours for the glutathione alone, or 3.3 hours for glutathione and hemoglobin. Again, phenylhydrazine caused a more rapid destruction of glutathione, 50 per cent being oxidized in 0.3 hour.

Measurements of the total (reduced and oxidized) glutathione in the experiments illustrated in Figures 3 and 4 show that it decreased to 60 or 70 per cent of its initial level in the presence of either phenylhydrazine or acetylphenylhydrazine and hemoglobin, but did not change appreciably by itself or with hemoglobin during the 4 hour period studied, findings confirming previous work by others (5).

3. The sequence of changes with oxidant drugs, and with in vitro aging. Determination of the relative rates of GSH oxidation and of methemoglobin, sulfhemoglobin, and precipitate formation were most informative with acetylphenylhydrazine, since the changes were too rapid with phenylhydrazine for adequate study. Figure 5 shows a replot of the GSH measurements of Figure 4, this time as per cent conversion to oxidized glutathione 
(GSSG) together with the percentage of the hemoglobin converted to methemoglobin, sulfhemoglobin or precipitate. Whereas both GSH oxidation to GSSG and hemoglobin oxidation to methemoglobin occurred early, no sulfhemoglobin or precipitated hemoglobin appeared until almost all GSH had been oxidized. However, the rate of GSH oxidation proceeded somewhat more rapidly than did methemoglobin formation, so that the chronological sequence was: 1) GSH oxidation, 2) methemoglobin formation, 3) sulfhemoglobin formation and 4) precipitation.

A similar, although more prolonged time course, is seen when glutathione is aged in vitro with hemoglobin and no oxidant drugs. Figure 6 illustrates an experiment in which $1 \mathrm{mM}$ hemoglobin was incubated at $37^{\circ} \mathrm{C}$ under sterile conditions with $1 \mathrm{mM}$ glutathione, at $\mathrm{pH} 7.4$. It can be seen that, as in the presence of acetylphenylhydrazine, methemoglobin accumulated somewhat more slowly than did GSSG. As in Figure 3, GSH was 50 per cent oxidized in about 3 hours, whereas methemoglobin increased only slightly in this period. During the period of observation no sulfhemoglobin or precipitate formed, and hemoglobin sulfhydryls remained constant. The total glutathione level remained constant until after 24 hours, whereupon it began to decline and was half gone in 72 hours.

Analogous results are obtained if washed red cells from freshly defibrinated blood are incubated under sterile conditions in normal saline and glutathione levels are measured on the whole suspension. This was done and once again it was found that the oxidation of glutathione proceeded more rapidly than the formation of methemoglobin. Total glutathione decreased somewhat faster in the red cells (half-disappearance, 48 hours) than in a hemoglobin solution. In a parallel experiment the addition of $100 \mathrm{mg}$ per $100 \mathrm{ml}$ glucose to the initial isotonic saline delayed the entire process by approximately 24 hours.

4. Reactions between glutathione and hemoglobin derivatives. The interaction of various hemo-

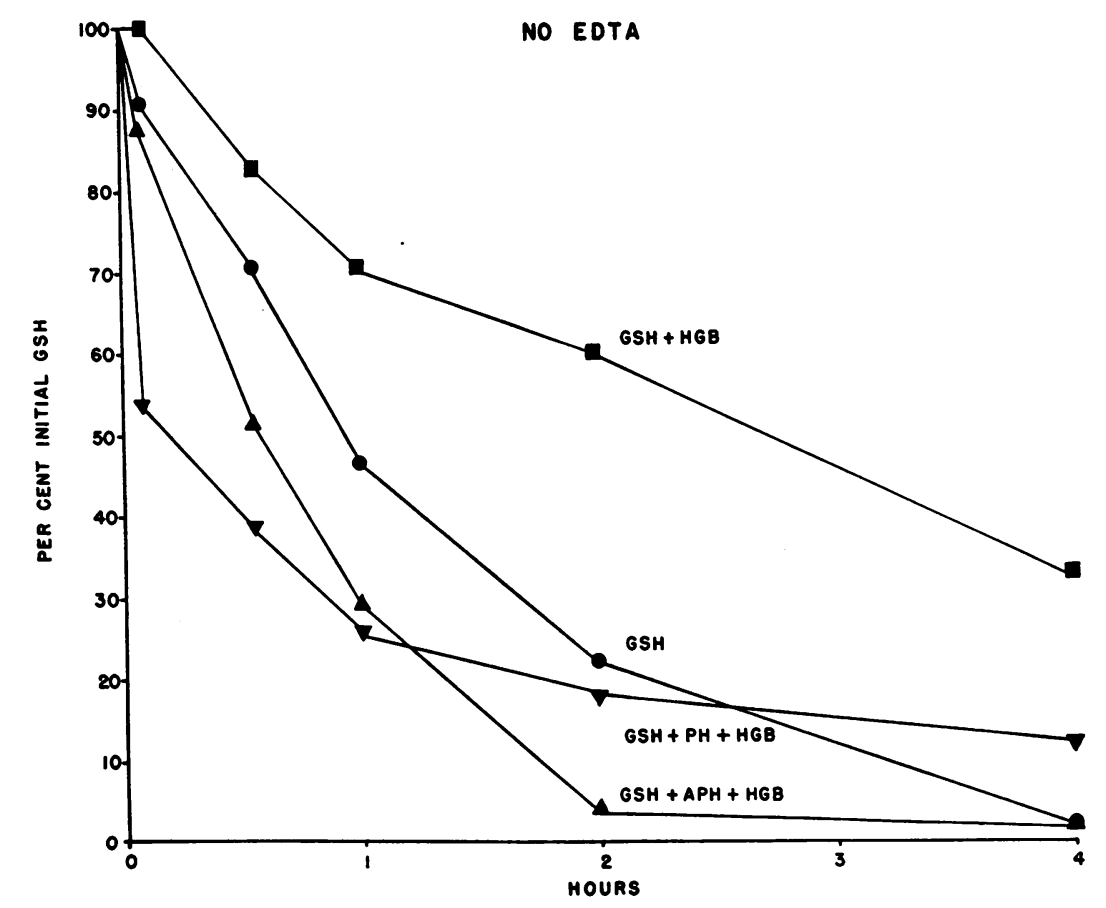

Fig. 3. The oxidation of GSH in air, at pH $7.4,37^{\circ} \mathrm{C}$, without EDTA, bUt WITH EQUIMOLAR HEMOGLOBIN $\boldsymbol{\square}$, WITH HEMOGLOBIN AND ACETYLPHENYLHYDRAZINE $\boldsymbol{\Delta}$, OR WITH HEMOGLOBIN AND PHENYLHYDRAZINE $\boldsymbol{\nabla}$, AS COMPARED WITH THE oxidation of GSH ALONE $\bullet$. It can be seen that while hemoglobin alone protects GSH, hemoglobin catalyzed the oxidation of GSH by acetylphenylhydrazine and by phenylhydrazine (see Figures 1 and 2). 


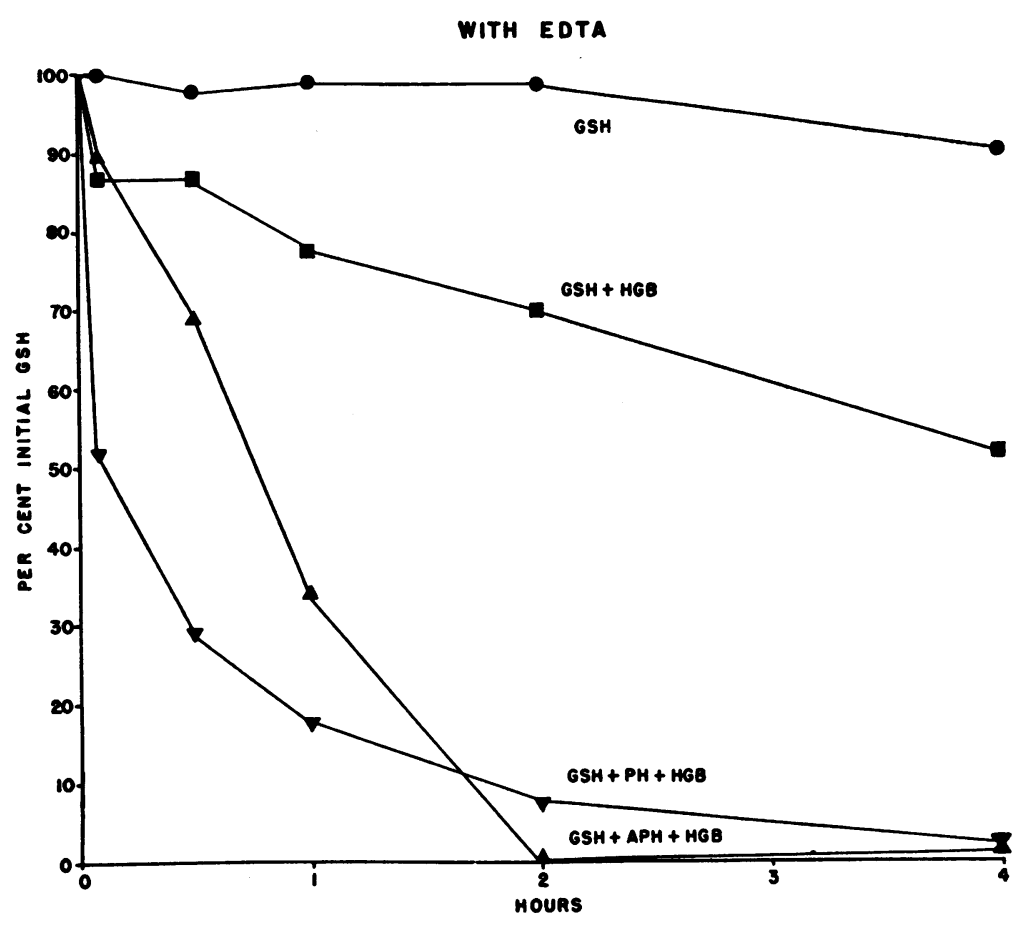

Fig. 4. The oxidation of GSH in aIR, AT PH 7.4, $37^{\circ} \mathrm{C}$, in the PRESENCE OF EDTA, EITHER ALONE $\bullet$ OR WITH : EQUIMOLAR HEMOGLOBIN $\square$; HEMOGLOBIN AND ACETYLPHENYLHYDRAZINE $\triangle$; OR HEMOGLOBIN AND PHENYLHYDRAZINE $\boldsymbol{\nabla}$. Note that the protective action of hemoglobin on GSH alone is now not in evidence with EDTA, and that the effect of EDTA in slowing the rate of phenylhydrazine and acetylphenylhydrazine oxidation of GSH has been circumvented by hemoglobin.

globin derivatives with glutathione was studied in experiments in which these derivatives were incubated with GSH or GSSG at $\mathrm{pH} 7.4$ in the presence of 0.01 per cent EDTA at $37^{\circ}$ in air for 0.5 hour. The short incubation time was intended to minimize the effect of oxygen, since removal of $\mathrm{O}_{2}$ was not possible if oxyhemoglobin was to be studied. Methemoglobin was produced from oxyhemoglobin by the addition of 1.0 heme-equivalent of potassium ferricyanide followed by dialysis. Methemoglobin cyanide was produced similarly except that 1.0 heme-equivalent of neutralized sodium cyanide was added prior to dialysis. In this experiment $0.62 \mu$ mole of GSH was oxidized by each $\mu$ mole of methemoglobin, compared with 0.21 by carbon monoxyhemoglobin, 0.15 by oxyhemoglobin, and 0.11 by methemoglobin cyanide. On the other hand, only $0.03 \mu$ mole or less of GSSG was reduced per $\mu$ mole of each of the hemoglobin derivatives during this incubation period. Hence, methemoglobin leads to greater oxidation of glu- tathione than does oxyhemoglobin in air, although far less than a stoichiometric amount of sulfhydryl (4 $\mu$ moles) was oxidized during the time period studied. Since no reduced hemoglobin could be detected on reaction of GSH with methemoglobin, it appears that GSH was oxidized by molecular oxygen more efficiently in the presence of methemoglobin than of oxyhemoglobin. An inappreciable amount of GSSG was reduced by the 4 ferrohemes and 6 sulfhydryls of hemoglobin.

\section{Effect of glutathione on the oxidative destruction of hemoglobin}

In addition to the sequential relationship of glutathione and hemoglobin oxidation, as described in the previous section, evidence of a protective role of glutathione is provided by study of its inhibition of the oxidative destruction of hemoglobin.

The destructive effect of phenyhydrazine on hemoglobin in solutions containing equimolar re- 


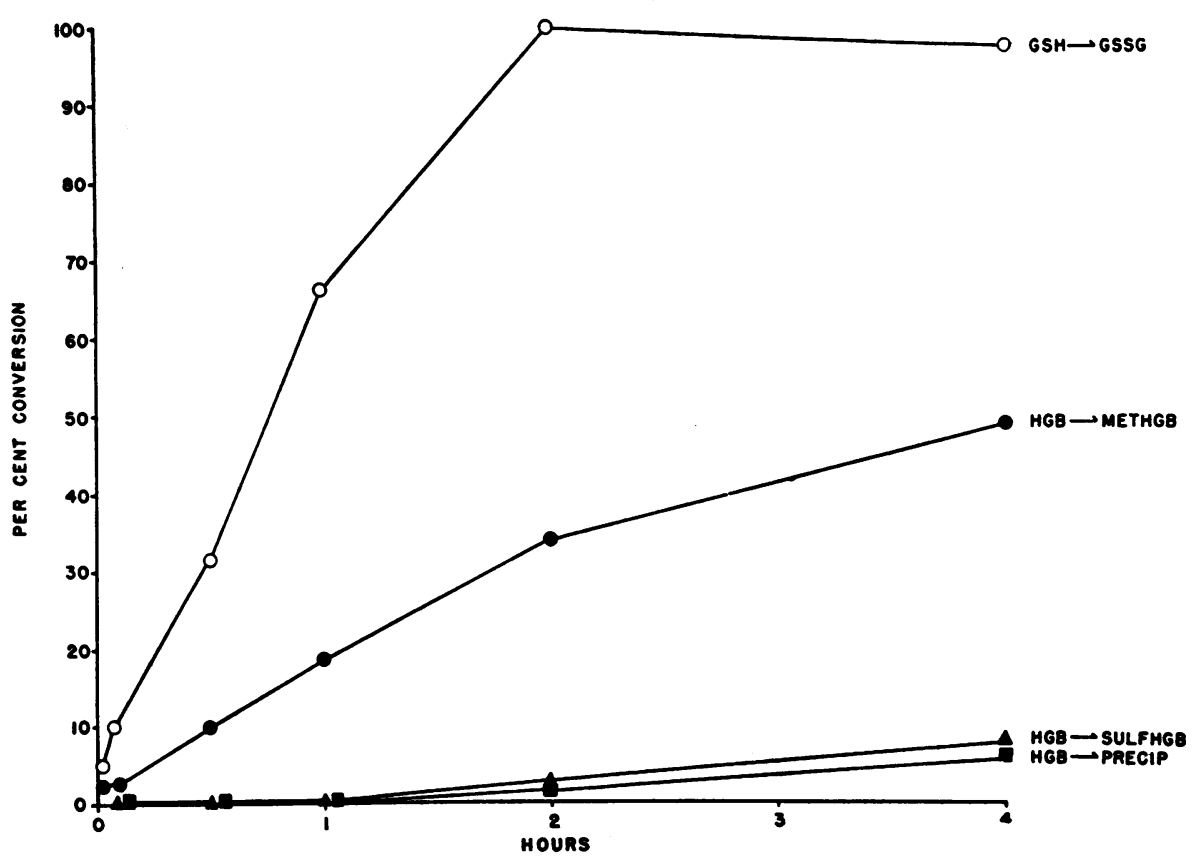

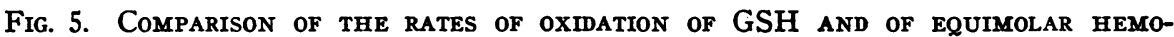
GLOBIN BY ACETYLPHENYLH YDRAZINE IN AIR. The data are from the same experiments as that illustrated in Figure 4. Note that GSH oxidation proceeds more rapidly than the conversion of hemoglobin to methemoglobin: GSH was half-oxidized in 45 minutes, hemoglobin half-oxidized in 4 hours. Further oxidative denaturation of hemoglobin (sulfhemoglobin formation and precipitation) occurred much more slowly.

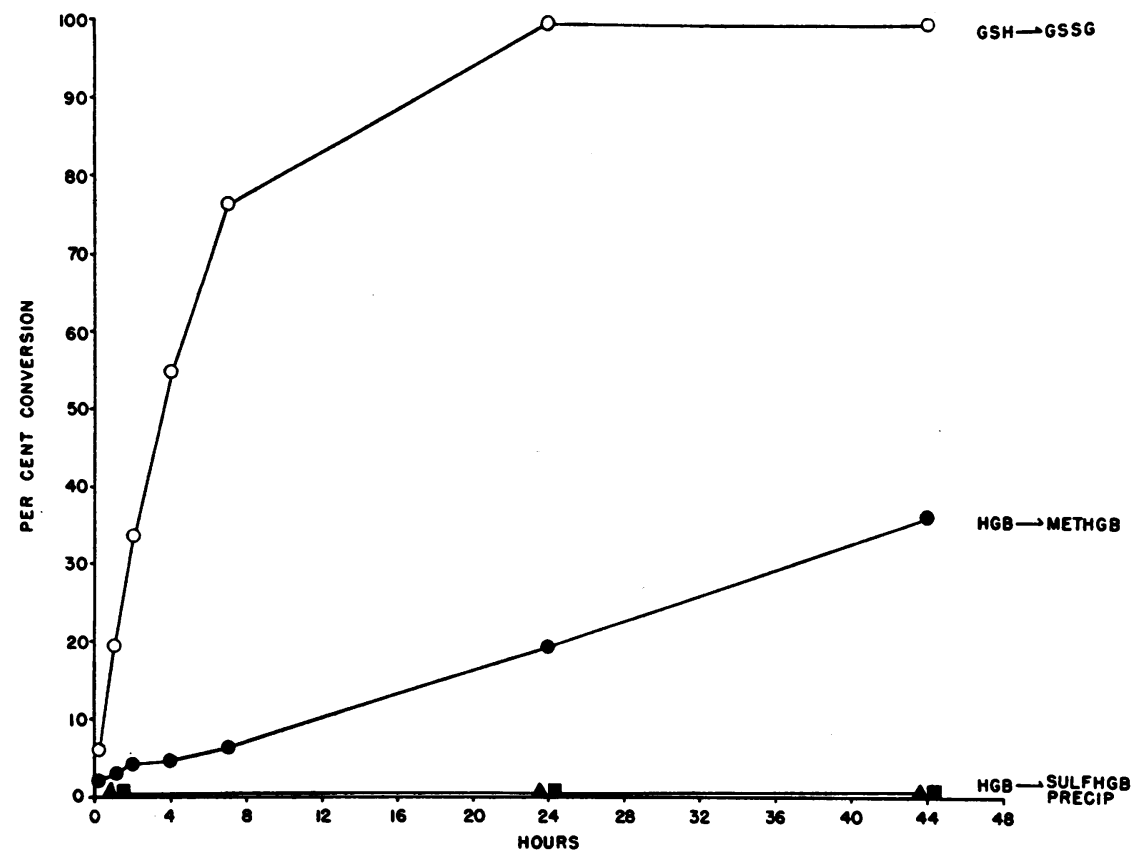

Fig. 6. Comparison of the rates of oxidation of GSH and of equimolar heMOGLOBIN ON PROLONGED STERILE INCUBATION IN AIR AT $37^{\circ} \mathrm{C}$. As in the presence of acetylphenylhydrazine (Figure 5), GSH oxidation proceeds more rapidly than methemoglobin formation. In this period of time virtually no sulfhemoglobin or precipitate formed. 


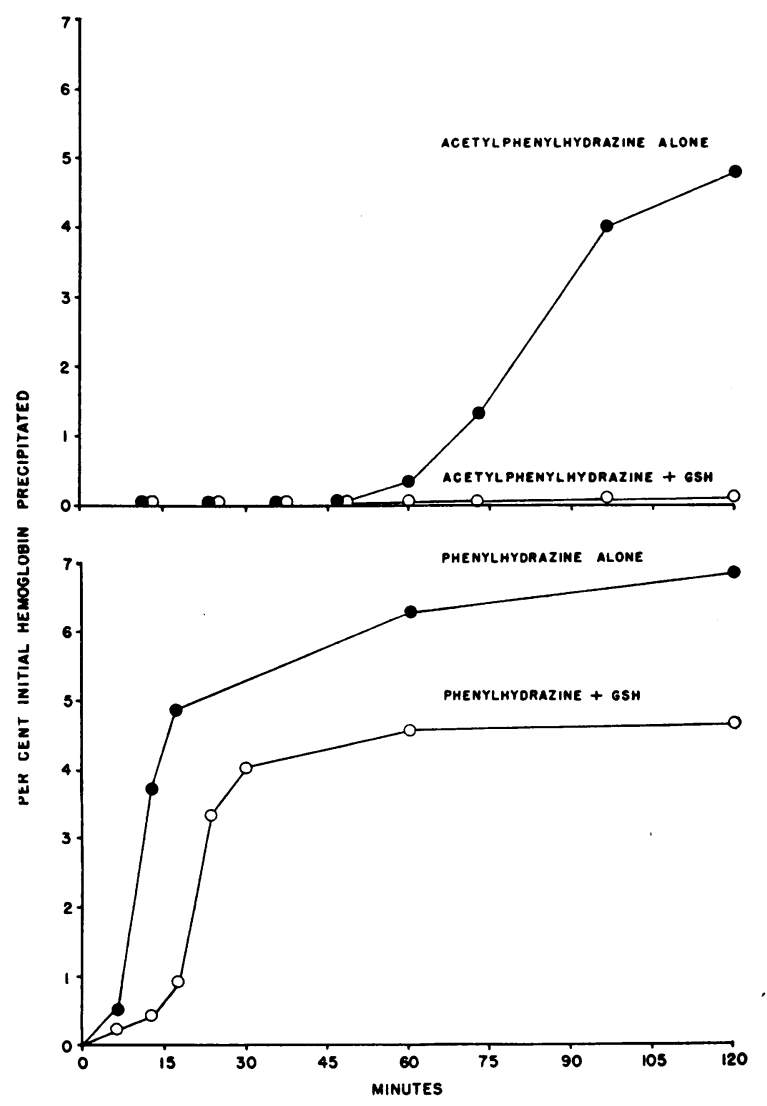

Fig. 7. Effect of GSH on the precipitation of heMOGLOBIN BY ACETYLPHENYLHYDRAZINE (ABOVE) AND BY PHENYLHYDRAZINE (BELOW). At 6-minute intervals, half-millimolar amounts of GSH were added to the incubation mixture of $1 \mathrm{mM}$ hemoglobin and $20 \mathrm{mM}$ hydrazine derivative. A similar result was obtained when all of the GSH $(10 \mathrm{mM})$ was added at the onset. Note the greater suppression of acetylphenylhydrazine than of phenylhydrazine.

duced glutathione ${ }^{4}$ was inhibited, as compared with its effect on hemoglobin alone. Glutathione in such systems decreased the formation of methemoglobin by 30 to 40 per cent and, as shown in Figure 7 , inhibited the rate of formation of precipitate. Larger amounts of glutathione produced greater inhibition but with a diminishing increment of effectiveness. GSH inhibited acetylphenylhydrazine more strikingly than it did phenylhydrazine. As indicated in Figure 7, the repeated addition of amounts of GSH (which were half the millimoles of hemoglobin present) completely

4 The figure 68,000 was employed for the molecular weight of hemoglobin. Note that the normal concentration in red cells of hemoglobin is approximately $5 \mathrm{mM}$ and that of glutathione is 2 to $3 \mathrm{mM}$. blocked precipitation of hemoglobin by a 20 molar ratio of acetylphenylhydrazine. Methemoglobin formation was diminished, but not abolished, by GSH. Oxidized glutathione had no effect on the action of either hydrazine compound or hemoglobin.

In addition to inhibiting the quantity of hemoglobin precipitated by oxidant compounds, GSH, but not GSSG, caused two qualitative changes in the precipitate. Grossly, hemoglobin precipitated by phenylhydrazine in the presence of GSH or cysteine, formed coarse aggregrates of granules, as contrasted to the finely dispersed aggregates appearing in the absence of GSH. A second effect of GSH was to increase the size of the individual granules formed, as shown in Figure 8. Granules of hemoglobin precipitated by phenylhydrazine reach a diameter of from 1 to $2 \mu$. In the presence of GSH (but not of GSSG) such granules generally grew to a diameter of 2 to $3 \mu$, and sometimes to $4 \mu$. Cysteine, but not cystine, also had this effect. Whereas the effect of thiols such as GSH and cysteine on the gross aggregation of hemoglobin appeared to be unique, their effect on the microscopic size of the individual granules was apparently a function of the slower rate of granule formation. This interpretation, characteristic of crystal formation, was suggested by the finding that granules of hemoglobin precipitated by the slowly-active acetylphenylhydrazine were larger than those caused by the rapidly-active phenylhydrazine. Furthermore, granules formed within a short period by high concentrations of a given oxidant compound were smaller than those formed over long periods by low concentrations.

When solutions of crystallized hemoglobin were treated with GSH, dialyzed free of GSH, and then exposed to phenylhydrazine, no effect of the GSH-pretreatment was manifest. Suspension of phenylhydrazine-precipitated hemoglobin in solutions of GSH did not affect the appearance of the precipitate, but caused a slight increase in its weight. The same was true when thioglycollate or mercaptoethanol was added to the precipitate.

\section{Effect of sulfhydryl-blocking agents on hemoglobin solutions and on red cells}

1. Precipitation of hemoglobin. Most studies employed the organic mercurial $p$-chloromercuribenzoate, a compound having a strong primary 

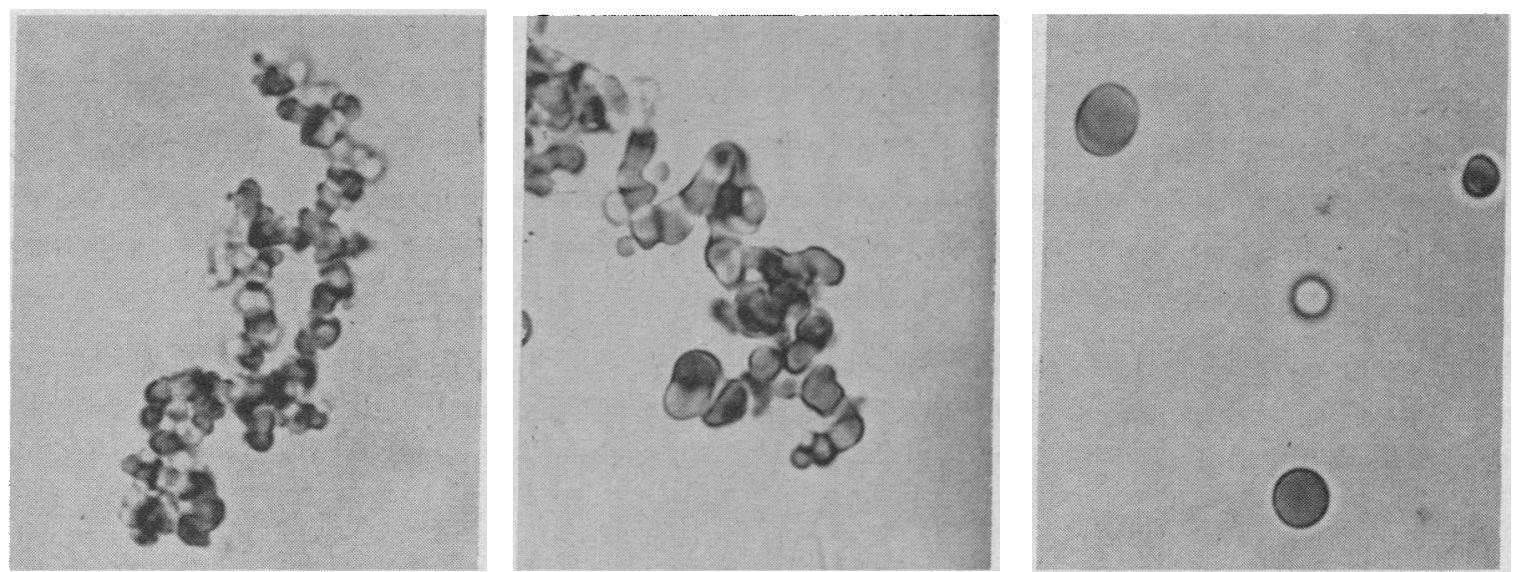

Fig. 8. EFFECT OF GSH ON THE SIZE OF THE GRANULES OF HEMOGLOBIN PRECIPITATEd BY PHENYLHYDRAZINE. Phenylhydrazine alone (left) produced hemoglobin granules which grew to a diameter of 1 to $2 \mu$. The granules found when phenylhydrazine acted in the presence of GSH (middle and right) usually ranged in diameter up to 3 $\mu$ (middle) and occasionally to $4 \mu$ (right). These variations in the size of granules of precipitated hemoglobin occurring without and with GSH are analogous to those encountered in GSH unstable red cells, and in normal red cells, respectively. Magnification $\times 2000$.

affinity for sulfhydryl groups (11). The addition of PCMB to solutions of crystalline hemoglobin caused the gradual appearance of a red precipitate which consisted of granules that, apart from their color, were identical in appearance with those caused by oxidant compounds. This precipitation could be blocked stoichiometrically by GSH and did not occur at $0^{\circ} \mathrm{C}$ or under an atmosphere of carbon monoxide. GSH added to washed suspensions of hemoglobin precipitated by PCMB diminished the granule size but only partially solubilized the precipitate. As shown in the lower portion of Figure 9, up to 2 moles of PCMB per mole of hemoglobin caused essentially no precipitation of hemoglobin in 3 hours at $37^{\circ} \mathrm{C}$. However, a molar ratio of PCMB in excess of 2 did cause precipitation to occur, beginning within 1 hour of admixture and proportional in amount to the dose of PCMB.

2. Heinz body formation and spherocytosis caused by PCMB. The ability of PCMB to hemolyze red cells has been well established by others (18). In the present studies, when to buffered suspensions of washed red cells equal amounts of 1 to $10 \mathrm{mM}$ PCMB were added, the red cells were observed by microscopy to become spherical, to display progressively increasing osmotic fragility and later to hemolyze. Shortly prior to actual lysis, when the red cells manifested extreme osmotic fragility, fine marginal inclusion bodies, which stained dark blue with crystal violet, became visible. These inclusions became heavier as actual

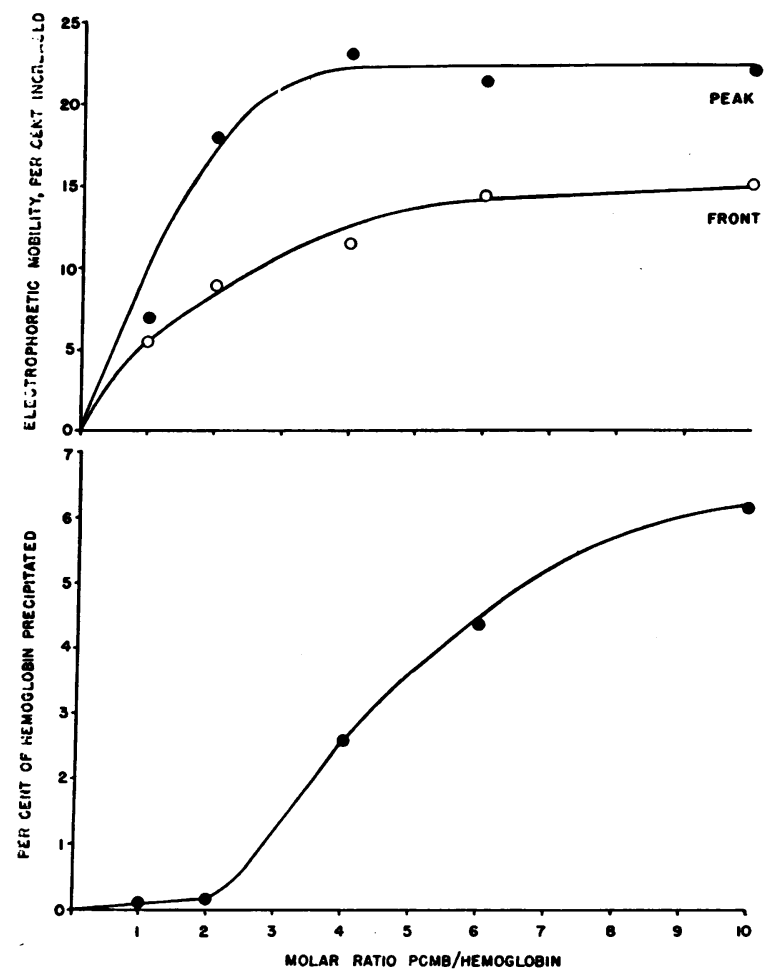

Fig. 9. INCREASE IN THE ELECTROPHORETIC MOBILITY (ABOVE) AND PRECIPITATION (BELOW) OF HEMOGLOBIN EXPOSED TO THE SULFHYDRYL-BLOCKING AGENT, $p$-CHLOROMERCURIBENZOATE (PCMB). Electrophoretic mobility in $0.05 \mathrm{M}$ barbital buffer, $\mathrm{pH} 8.6$, is expressed as the per cent increase over that of control (untreated) hemoglobin. Most of the increase in mobility, both of the main hemoglobin "peak" and of the fast-moving "front," was achieved with 2 moles of PCMB per mole of hemoglobin, whereas precipitation did not occur until more than 2 moles of PCMB had been added. 
lysis commenced and resembled Heinz bodies. As depicted in Figure 10, this sequence differed from that observed with phenylhydrazine and related compounds not only in the lack of methemoglobin and sulfhemoglobin formation, but also in that, with PCMB, Heinz bodies appeared well after the onset of spherocytosis whereas with phenylhydrazine, the first appearance of Heinz bodies occurred long before spherocytosis developed. In this respect the effect of PCMB was analogous to the sequence of spherocytosis and Heinz body formation observed during prolonged storage of red cells at $37^{\circ} \mathrm{C}$ in vitro (1).

3. Changes in electrophoretic behavior of hemoglobin. Whether added to solutions of hemoglobin or to red cells, PCMB caused an increase in the electrophoretic mobility of hemoglobin on filter paper at $\mathrm{pH}$ 8.6. As shown in the upper portion of Figure 9, the increase in mobility of the main component at its color "peak" was evident on the addition of only 1 mole of PCMB per mole of hemoglobin and was almost maximally increased by the addition of 2 moles, so that only slight further increases appeared with up to 10 moles of PCMB.
As shown in the same figure, the fastest detectable portion of the fast-moving component ("front") showed a similar increased mobility on the addition of PCMB. The fast component increased only slightly in amount at the expense of the main component. Another sulfhydryl-blocking agent, $\mathrm{N}$-ethylmaleimide, had a similar effect.

4. Potentiation of phenylhydrazine by PCMB. When phenylhydrazine and PCMB were simultaneously incubated with solutions of crystalline hemoglobin, the amount of hemoglobin precipitated was greatly in excess of the combined weight of the precipitates produced by these agents when added separtely. As shown in Figure 11, the addition of 2 moles of phenylhydrazine per mole of hemoglobin caused less than 2 per cent of the hemoglobin to precipitate in a period of 2 hours in the absence of PCMB. The added presence of up to 2 moles of $\mathrm{PCMB}$ only slightly increased precipitation. However, with slightly larger amounts of PCMB, the degradation of hemoglobin was strikingly potentiated, with four to five times as much precipitate forming as after the addition of both of these compounds separately.

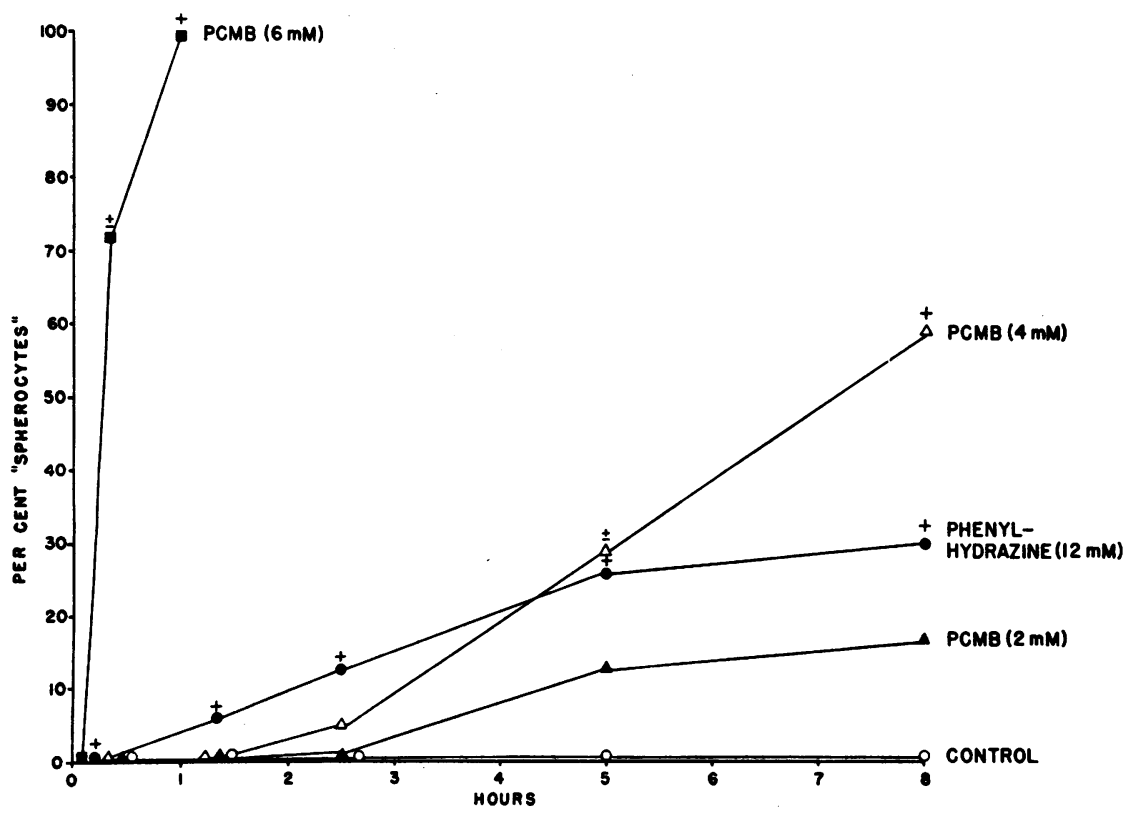

Fig. 10. Spherocytosis and Heinz body formation in Red cells exposed to the SULFH YDRYL-BLOCKING AGENT, $p$-CHLOROMERCURIBENZOATE (PCMB). Spherocytosis was quantitated arbitrarily by the per cent lysis in 0.50 per cent saline less the per cent lysis in 0.90 per cent saline $(t=$ presence of Heinz bodies). Note that while PCMB had a marked effect in causing sphering of red cells, Heinz bodies were a late event; with phenylhydrazine, however, the reverse was true. 


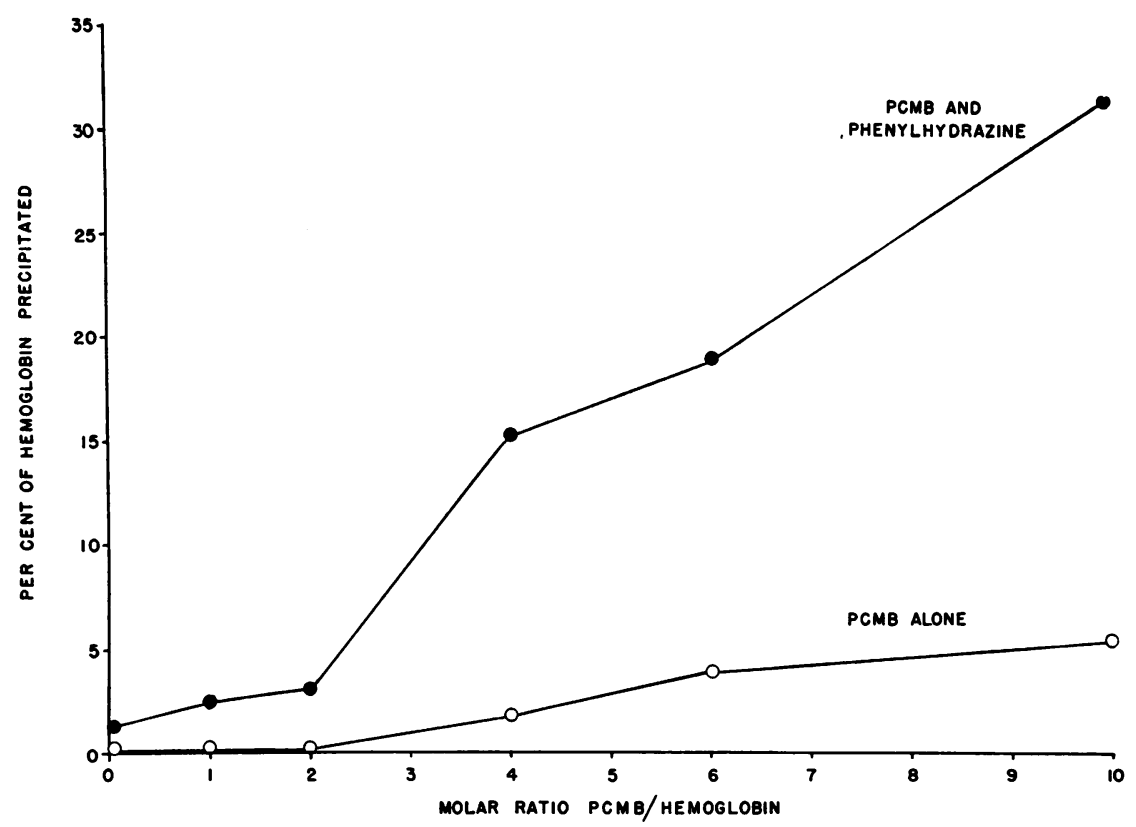

Fig. 11. Potentiation of the action of Phenylhydrazine on hemoglobin by THE SUlfHydRYl-blocking agent, p-Chloromercuribenzoate (PCMB). Although this dose of phenylhydrazine alone $(\bullet:$ first point) precipitated only about 2 per cent of hemoglobin, and as much as 10 moles of PCMB per mole of hemoglobin $(O$ : last point) precipitated only 6 per cent, the combination of phenylhydrazine and 10 moles of PCMB precipitated 32 per cent of the hemoglobin.

This potentiating action of PCMB was blocked by the prior addition of equimolar amounts of $\mathrm{GSH}$ to the reaction mixtures.

\section{Formation of hemoglobin-GSH mixed disulfides}

The ability of hemoglobin to bind GSH is demonstrated in an experiment presented in Table III. When hemoglobin was incubated with $2 / 3$ mole of $\mathrm{GS}^{35} \mathrm{H}$ per mole of hemoglobin at $37^{\circ} \mathrm{C}$ for 2 hours, a small but appreciable fraction (8.54 per cent) of the $\mathrm{GS}^{35} \mathrm{H}$ became precipitable by TCA along with hemoglobin, whereas virtually no
$\mathrm{GS}^{35} \mathrm{H}$ was TCA-precipitable as the result of incubation with hemoglobin at $0^{\circ} \mathrm{C}$. The presence of phenylhydrazine in the reaction mixture caused almost one-quarter of the $\mathrm{GS}^{35} \mathrm{H}$ (23.32 per cent) to attach to hemoglobin provided $\mathrm{GS}^{35} \mathrm{H}$ was present during the incubation period. However, if $\mathrm{GS}^{35} \mathrm{H}$ was added after the incubation period, but before TCA precipitation, there was no appreciable attachment of the label. That $\mathrm{GS}^{35} \mathrm{H}$ was largely bound to hemoglobin by disulfide linkage is suggested by the fact that about 80 per cent of the bound $\mathrm{GS}^{35} \mathrm{H}$ was removed from hemoglo-

TABLE III

Formation of hemoglobin-GSH mixed disulfides

\begin{tabular}{|c|c|c|c|c|c|c|c|c|}
\hline \multirow[b]{2}{*}{$\begin{array}{l}\text { Hemo- } \\
\text { globin }\end{array}$} & \multicolumn{2}{|c|}{ Radioactive GSH } & \multirow[b]{2}{*}{$\begin{array}{l}\text { Phenyl- } \\
\text { hydrazine }\end{array}$} & \multirow[b]{2}{*}{ Temp. } & \multicolumn{2}{|c|}{$\% \underset{\text { precipitate }}{\mathrm{GS}^{35} \mathrm{H} \text { in } \mathrm{TCA}}$} & \multicolumn{2}{|c|}{$\begin{array}{c}\% \text { Crecipitate } \\
\text { preGSH in TCA }\end{array}$} \\
\hline & $\begin{array}{l}\text { Added } \\
\text { before } \\
\text { incub. }\end{array}$ & $\begin{array}{c}\text { Added } \\
\text { after } 2 \mathrm{hrs} \\
\text { incub. }\end{array}$ & & & $\begin{array}{l}\text { Glycollic } \\
\text { acid- } \\
\text { treated }\end{array}$ & $\begin{array}{l}\text { Thiogly- } \\
\text { collic } \\
\text { acid- } \\
\text { treated }\end{array}$ & $\begin{array}{l}\text { Glycollic } \\
\text { acid- } \\
\text { treated }\end{array}$ & $\begin{array}{l}\text { Thiogly- } \\
\text { collic } \\
\text { acid- } \\
\text { treated }\end{array}$ \\
\hline $\begin{array}{l}+ \\
+ \\
+ \\
+\end{array}$ & $\begin{array}{l}+ \\
+ \\
+\end{array}$ & + & $\begin{array}{l}+ \\
+\end{array}$ & $\begin{array}{r}0 \\
37 \\
37 \\
37\end{array}$ & $\begin{array}{r}0.18 \\
8.54 \\
23.32 \\
1.37\end{array}$ & $\begin{array}{l}0.29 \\
1.54 \\
5.11 \\
0.27\end{array}$ & $\begin{array}{r}0.22 \\
3.96 \\
17.40 \\
1.42\end{array}$ & $\begin{array}{l}0.37 \\
1.44 \\
5.25 \\
0.73\end{array}$ \\
\hline
\end{tabular}


HEMOGLOBIN $--s^{35}$

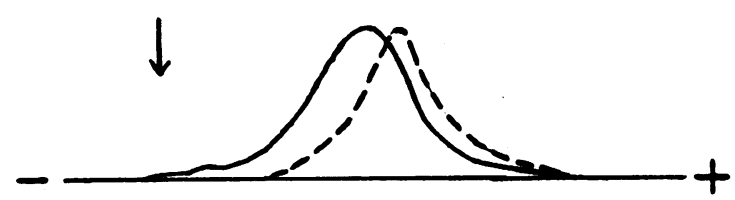

HEMOGLOBIN $--c^{14}$

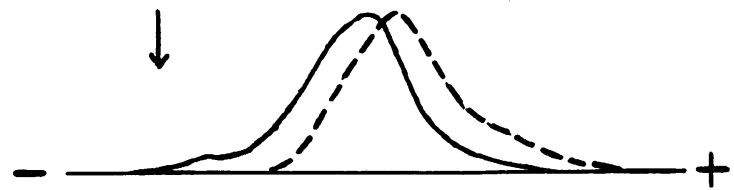

Fig. 12. Electrophoretic localization of hemogloBIN-BOUND GSH IN THE FAST COMPONENT OF HEMOGLOBIN. GSH labeled either with $\mathrm{S}^{35}$ (top) or $\mathrm{C}^{14}$ (bottom) became bound to hemoglobin during oxidation by phenylhydrazine. After dialysis, electrophoresis of the hemoglobin in $0.05 \mathrm{M}$ barbital buffer, $\mathrm{pH} 8.6$, followed by autoradiography, revealed that the GSH radioactivity (interrupted lines) localized in the faster-moving components of the hemoglobin (solid lines). bin by thiollic reduction with thioglycollic acid, as compared with a control similarly treated with glycollic acid.

Studies with $\mathrm{C}^{14}$-labeled GSH revealed a similar, albeit somewhat smaller, binding of $\mathrm{C}^{14}$ than of $\mathrm{S}^{35}$ to hemoglobin. This suggests that most of the bound material is intact glutathione but that a portion (as much as 25 per cent) of the hemoglobin-bound $\mathrm{S}^{35}$ may involve inorganic sulfur derived from the GSH preparation.

The specific activity of the portion of hemoglobin precipitated by phenylhydrazine in the presence of either $\mathrm{GS}^{35} \mathrm{H}$ or $\mathrm{C}^{14}$-GSH was from 4 to 5 times that of the total hemoglobin (i.e., that precipitated by TCA). Thus, the most severely denatured (precipitated) hemoglobin had bound much more GSH than had the still-soluble hemoglobin.

After dialysis of the hemoglobin exposed to phenylhydrazine in the presence of labeled GSH, both $\mathrm{GS}^{35} \mathrm{H}$ and $\mathrm{C}^{14}$-GSH moved with hemoglobin on filter paper electrophoresis in $0.05 \mathrm{M}$ barbital

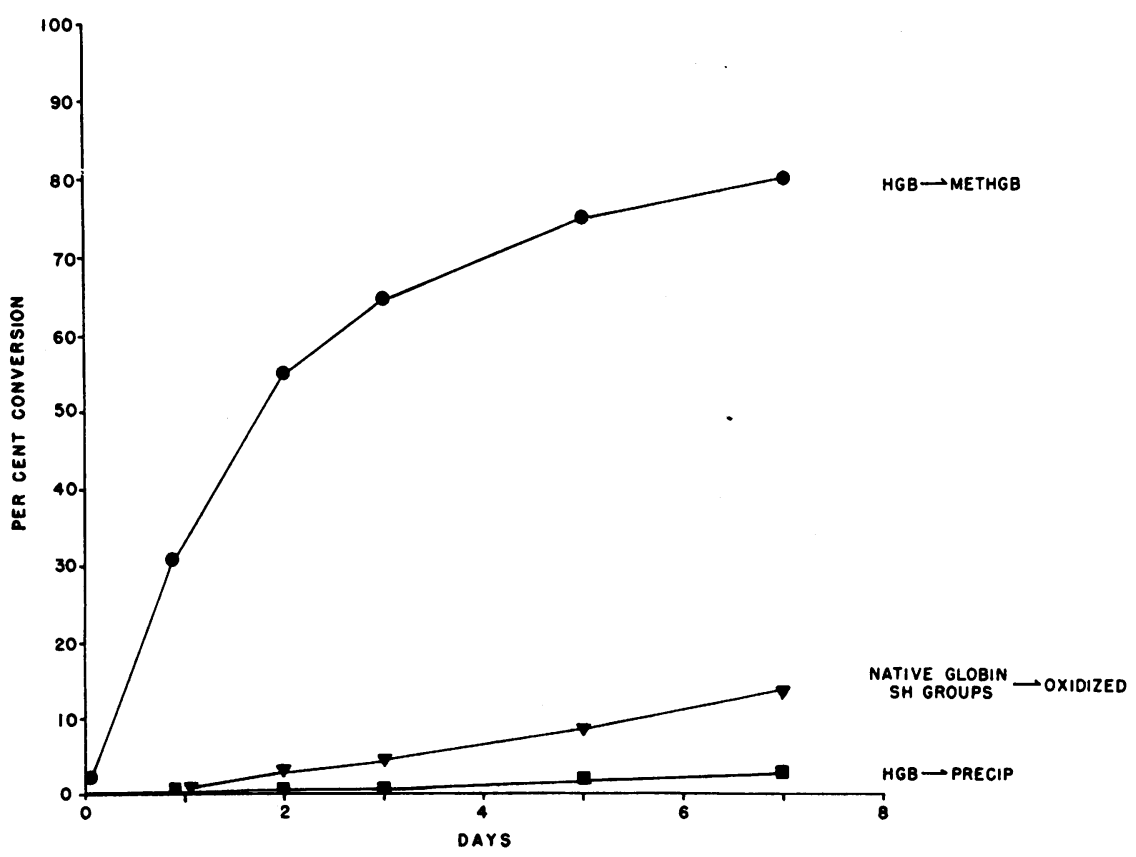

Fig. 13. Comparison of MEthemoglobin formation, oxidation of the tWo SUlfHYDRYL GROUPS OF NATIVE HEMOGLOBIN, AND PRECIPITATE FORMATION ON PROLONGED STERILE INCUBATION OF HEMOGLOBIN IN AIR AT $37^{\circ} \mathrm{C}$. Note that methemoglobin formation comes first, then oxidation of native sulfhydryls which in turn precedes precipitation of hemoglobin. It will be recalled that when GSH was present in such a system, it was completely oxidized during the first day (Figure 6). 
buffer, $\mathrm{pH} 8.6$ (Figure 12). As this figure indicates, the radioactivity localized largely with the augmented fast-moving component of hemoglobin.

\section{Measurement of hemoglobin mercury-binding sites}

Our experience with mercuric chloride was similar to that of previous workers $(19,20)$ since a value of 2 mercury-binding groups per native (i.e., undenatured) hemoglobin molecule was obtained reproducibly. Measurements of total mercury-binding groups in $8 \mathrm{M}$ urea frequently gave values less than the expected maximal figure of 6 (19) per hemoglobin molecule, due either to the uncertain stoichiometry of mercury, or to the lability of sulfhydryl groups under these conditions (20). Measurements of total sulfhydryls under experimental conditions here were made alternately with control hemoglobin samples, giving values of 5 to 6 mercuric ions per hemoglobin molecule.

Although previous workers have observed a fall in hemoglobin sulfhydryl groups on storage at $0^{\circ}(19)$, no systematic study of this phenomenon has been undertaken by others. Figure 13 shows the results of amperometric titration of the mercury-binding groups of hemoglobin (undenatured by urea) which had been aged in vitro at $37^{\circ} \mathrm{C}$ for varying lengths of time. The percentage of the initial value of 2.04 mercury-binding groups per hemoglobin molecule is compared with percentage conversion to methemoglobin, and percentage precipitation. It is seen that oxidation of the heme groups (methemoglobin formation) precedes oxidation of the globin sulfhydryl groups, whereas the latter is synchronous with precipitation. In an additional series of experiments the precipitate formed from hemoglobin aged 8 days at $37^{\circ} \mathrm{C}$ was dissolved in $8 \mathrm{M}$ urea, and its mercury-binding groups were compared
TABLE IV

Effect of incubation on the total mercury-binding groups of hemoglobin

\begin{tabular}{clc}
\hline \hline $\begin{array}{c}\text { Incubation } \\
\text { conditions }\end{array}$ & \multicolumn{1}{c}{$\begin{array}{c}\text { Physical state of } \\
\text { hemoglobin }\end{array}$} & $\begin{array}{c}\text { Hemoglobin } \\
\text { total mercury- } \\
\text { binding groups } \\
\text { titrated }\end{array}$ \\
\hline $0^{\circ} \mathrm{C}, 8$ days & Soluble & 5.8 \\
$37^{\circ} \mathrm{C}, 8$ days & $\begin{array}{c}\text { Partly soluble } \\
\text { a) Soluble supernate }\end{array}$ & 5.7 \\
& b) Precipitate & 1.2 \\
\hline
\end{tabular}

with those in $8 \mathrm{M}$ urea of the supernatant hemoglobin as well as of hemoglobin kept at $0^{\circ} \mathrm{C}$ for the same period of time. The results are shown in Table IV. It can be seen that the hemoglobinderived precipitate has lost nearly all of its sulfhydryl groups. Not all forms of precipitation of hemoglobin result in loss of so many sulfhydryl groups. Thus, acetone precipitation of the supernatant hemoglobin incubated at $37^{\circ} \mathrm{C}$ or of the hemoglobin stored at $0^{\circ} \mathrm{C}$ gave values between 3 and 4 binding groups per hemoglobin molecule.

A similar decrease in sulfhydryl groups was found with hemoglobin treated with excess alkaline ferricyanide. In Table $\mathrm{V}$ it is seen that the supernatant hemoglobin from solutions treated with 14 moles of ferricyanide per mole of hemoglobin, at $\mathrm{pH} 9.2$ for 1 hour, lost the 2 sulfhydryl groups available for mercury titration in the native protein, but retained 4 on titration in $8 \mathrm{M}$ urea. The precipitate had lost almost all mercury-binding groups. Apparently, then, oxidation of the 2 outer sulfhydryl groups, during a short time period, is compatible with solubility, but further oxidation results in precipitation (1).

In order to study the effects of phenylhydrazine on the mercury-binding groups of hemoglobin $1 \mathrm{mM}$ of hemoglobin was treated with $4 \mathrm{mM}$ of phenylhydrazine for 4 hours at $37^{\circ} \mathrm{C}$ in phosphate buffer $\mathrm{pH}$ 7.4, then dialyzed overnight

TABLE V

Effect of ferricyanide on the mercury-binding groups of hemoglobin

\begin{tabular}{clcc}
\hline $\begin{array}{c}\text { Experimental } \\
\text { conditions }\end{array}$ & \multicolumn{1}{c}{$\begin{array}{c}\text { Physical state of } \\
\text { hemoglobin }\end{array}$} & \multicolumn{2}{c}{$\begin{array}{c}\text { Hemoglobin mercury- } \\
\text { binding groups titrated }\end{array}$} \\
\hline $\begin{array}{c}\text { Untreated hemoglobin } \\
\text { Alkaline ferricyanide- } \\
\text { treated hemoglobin }\end{array}$ & $\begin{array}{l}\text { Soluble } \\
\text { Partly soluble }\end{array}$ & 1.9 & Total \\
\hline & $\begin{array}{l}\text { a) Soluble supernate } \\
\text { b) Precipitate }\end{array}$ & 0 & 5.9 \\
\hline
\end{tabular}


TABLE VI

Effect of phenylhydrazine on the mercury-binding groups of hemoglobin

\begin{tabular}{llcc}
\hline \hline & & \multicolumn{2}{c}{$\begin{array}{c}\text { Hemoglobin mercury- } \\
\text { binding groups titrated }\end{array}$} \\
\cline { 2 - 3 } Experimental conditions & \multicolumn{1}{c|}{$\begin{array}{c}\text { Phycal state of } \\
\text { hemoglobin }\end{array}$} & "Native" & Total \\
\hline $\begin{array}{l}\text { Untreated hemoglobin } \\
\text { Phenylhydrazine-treated } \\
\text { hemoglobin }\end{array}$ & $\begin{array}{l}\text { Soluble } \\
\text { Partly soluble }\end{array}$ & 1.9 & 5.9 \\
& $\begin{array}{l}\text { a) Soluble supernate } \\
\text { b) Precipitate }\end{array}$ & 1.7 & 5.6 \\
\end{tabular}

with mechanical stirring against 150 volumes of 0.85 per cent sodium chloride. As can be seen in Table VI, the number of mercury-binding groups of dialyzed, phenylhydrazine-treated hemoglobin is slightly lower than for untreated control hemoglobin, but considerably higher than for ferricyanide hemoglobin in which a like amount of precipitation had occurred. The mercury-binding groups of the hemoglobin precipitated by phenylhydrazine were diminished in number, but did not vanish as after precipitation by ferricyanide.

As $A_{I}$, the fast-moving component of hemoglobin on IRC 50 chromatography (13), is increased by in vitro aging and phenylhydrazine or alkaline ferricyanide treatment (1), it was of interest to determine the number of mercury-binding groups of this component. After chromatography of carbon monoxyhemoglobin in developer 2 (13) in which the cyanide had been replaced by an equivalent amount of sodium hydroxide, the components $A_{I}$ and $A_{I I}$ showed no difference in the mercury-binding groups, either of the native proteins or after urea denaturation. Moreover, when the amount of the front-running component was increased by alkaline ferricyanide treatment from 10 to 17 per cent, the number of titrable sulfhydryl groups was decreased equally in both $A_{I}$ and $\mathrm{A}_{\text {II }}$ hemoglobins, from 2.0 to 1.3 .

\section{DISCUSSION}

Prevention of hemolysis and of the precipitation of hemoglobin as Heinz bodies in the normal red cell requires the suppression of chemical equilibrium with molecular oxygen. Heme ferrous iron and thiol groups of globin and glutathione exist in an oxygenated environment which, if equilibrium were attained, would rapidly result in their oxidation. The following representative values $(21)$ of the oxidation potentials $\left(\mathrm{Eo}^{\prime}\right)$ of redox systems involving these substances (not all, it is true, for precisely the same conditions of $\mathrm{pH}$ and temperature) serve to indicate the relatively steep oxidative gradient found in the red cell : 0.2 atmosphere oxygen, $0.8 \mathrm{v}$; hemoglobin $\rightleftarrows$ methemoglobin, $0.140 \mathrm{v} ; \mathrm{GSH} \rightleftarrows \mathrm{GSSG}, 0.04$ v. The sulfhydryl groups of globin probably approximate the last two systems in oxidation potential, as may possibly the tyrosine and tryptophane residues of globin. Thus, if a redox equilibrium is permitted, electrons will flow from these red cell constituents to oxygen.

Fortunately for its survival, the red cell possesses many reducing systems which, as others have stressed (22), oppose the attainment of an intracellular redox equilibrium. Catalase destroys the reactive intermediate reduction product of oxygen-hydrogen peroxide (22). Methemoglobin reductase regenerates oxidized heme groups (23). Glutathione, which is synthesized (24) and kept reduced by complex enzyme systems (6), is present in fairly high concentrations and buffers hemoglobin and sulfhydryl-containing enzymes against oxidative destruction. As a result of these reducing enzyme systems in the red cell, the sequence of events during oxidative hemolysis may not proceed in the same order as would be anticipated from knowledge of the oxidation potential hierarchy defined above. Furthermore, oxidant compounds may possess special properties (as of charge or steric configuration) which may endow specificity of redox action. Ferricyanide, for example, oxidizes heme in pref-

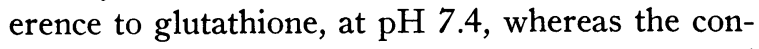
verse occurs with oxygen alone or oxygen and phenylhydrazine and related compounds. Finally, congenital defects in specific reducing systems of the red cell result in the accumulation of different oxidized products. A deficiency of a methe- 
moglobin reductase yields much methemoglobin but normal GSH by nitroprusside test (25). Such an accumulation of an oxidized product with a higher oxidation potential than other groups still reduced, does not invalidate the sequence to be described but merely demonstrates once again that the system is not normally in mobile equilibrium.

\section{Biochemical sequence during oxidative hemolysis and precipitation of hemoglobin}

However, despite this probability of variation, when hemoglobin solutions containing equimolar glutathione are exposed to oxygen, with or without oxidant drugs, a surprisingly regular sequence of events takes place, as has been described previously (1) and as Figures 6 and 7 further attest. The role of sulfhydryl groups in this series of events is the particular concern of the present discussion, because of their function in maintaining the integrity of red cell constituents.

The first step in the series of events leading to hemolysis by phenylhydrazine and related compounds appears to be the reaction of oxygen with these compounds to form oxidized derivatives. Evidence has been presented that this is catalyzed by hemoglobin as well as by trace metal ions. Next, the oxidized drug reacts with glutathione, ferrous hemes, and hemoglobin sulfhydryl groups, apparently in this order of decreasing reaction rate. It is likely that all of these reactions proceed simultaneously but that, because of their different reaction rates, those irreversible changes leading to sulfhemoglobin formation and hemoglobin precipitation are not apparent until glutathione has been completely oxidized.

1. Glutathione oxidation. It is well established that at a physiologic $\mathrm{pH}$, auto-oxidation of thiols occurs relatively rapidly unless "all traces of metals are removed, e.g., with a chelating agent" (11), a fact manifest in the present studies (Tables I and II). A report to the contrary (5) may be due to the use of unbuffered systems, since, as discussed earlier, thiols are relatively stable at an acid $\mathrm{pH}$ such as that of unbuffered GSH.

Hemoglobin added to GSH was shown to have two opposite roles: one, when alone, in protecting GSH from oxidation; and the second, in the pres- ence of oxidant drugs, in facilitating its destruction. When trace metal ions were removed by EDTA, as seen in Figure 4, the hemoglobin no longer was protective. Thus, GSH with EDTA present was more stable without than with hemoglobin. This suggests that the protective effect of hemoglobin when alone is a nonspecific metalbinding property similar to that of other proteins, albeit less efficient in this respect than EDTA.

The second role of hemoglobin as catalyst of GSH destruction with or without oxidant drugs can be studied by comparison of Figure 4 (hemoglobin as catalyst) and Figure 1 (trace metals as catalyst) with Figure 2 (control). Hemoglobin accelerates GSH destruction by oxidant drugs even more rapidly than do trace metal ions: there is a 5 minute half-life for GSH with hemoglobin and phenylhydrazine (Figure 4) versus a 30 minute half-life for GSH with trace metals and phenylhydrazine (Figure 1); and a 45 minute half-life of GSH with hemoglobin and acetylphenylhydrazine (Figure 4) as opposed to a 1 hour half-life with trace metals and acetylphenylhydrazine (Figure 1). That hemoglobin was more active than trace metals in facilitating destruction of GSH by oxidant compounds in these experiments may be due to its relatively greater concentration.

These findings differ in several respects from similarly-devised experiments previously reported by Beutler, Robson and Buttenwieser (5). These workers found that neither hemoglobin nor acetylphenylhydrazine alone caused oxidation of GSH, whereas hemoglobin either simultaneously or preliminarily incubated with acetylphenylhydrazine did oxidize GSH. They concluded that acetylphenylhydrazine did not per se destroy GSH but did so by producing an altered form of hemoglobin. The present studies, on the contrary, indicate that acetylphenylhydrazine alone oxidizes GSH once it has been converted under oxygen to an active form (Table I); this conversion is catalyzed by trace metals (Table II) or by hemoglobin $(1,26)$, but its action on GSH does not require trace metals (Table II). In a very comparable manner hemoglobin alone catalyzes GSH oxidation by oxygen and is also capable of forming oxidized derivatives which directly oxidize GSH. It is apparent that, unless controlled throughout, the buffering, metalbinding, and oxidase properties of hemoglobin may have conflicting experimental consequences. 
In red cells incubated under sterile conditions in vitro the oxidation of GSH followed by a fall in total glutathione is similar to that observed previously by other workers (27).

2. Heme oxidation. Proceeding at a slightly slower rate is the oxidation of the ferroheme groups of hemoglobin to form methemoglobin. Both phenylhydrazine and acetylphenylhydrazine are reducing agents, capable of reducing not only methemoglobin but also ferricyanide. Thus, it must be the oxidized products of these drugs that remove electrons from the ferrous iron hemoglobin $(26,28,29)$. It is of interest that in artificial mixtures, the relative proportions of glutathione and ferrous heme oxidized by acetylphenylhydrazine and oxygen (Figure 5) roughly correspond to what one would predict from their oxidation potentials listed above. Hence, it is likely that if an oxidant drug is present (Figure 5 ) or if sufficient time for incubation is allowed, when the specific reducing systems normally present in the red cell are removed ferroheme and glutathione are actually in equilibrium. However, this equilibrium is extremely sluggish in vitro as methemoglobin will oxidize only a small portion of GSH in 30 minutes, during which none of the methemoglobin is reduced. The previous report by others (30) of the reduction of methemoglobin by glutathione attests this slowness, the reduction of 0.7 equivalents of heme requiring 24 hours at room temperature even under carbon monoxide, which by binding the reduced hemoglobin favors the reaction as well as decreasing the auto-oxidation of GSH.

3. Globin oxidation. In view of the evidence obtained with $\mathrm{PCMB}$, and with alkaline ferricyanide (1), that sulfhydryl groups are involved in the oxidative destruction of the hemoglobin molecule, a direct measure of these groups was undertaken. Of the available methods, amperometric titration using the mercuric ion has been successfully applied to undenatured hemoglobin by Ingram (19) and by Allison and Cecil (20) with identical results indicating the presence of 2.2 mercuric ions per mole of hemoglobin. The higher values of some workers using silver have been attributed to nonspecificity of binding of this cation (31). Results on hemoglobin denatured with sodium dodecyl sulfate with mercuric ion have not been consistent in the literature $(19,20)$, probably because the divalent mercury ion may combine with either one or two sulfhydryl groups in denatured hemoglobin.

Accompanying the oxidation of the ferroheme groups, but at a slower rate, the two sulfhydryl groups exposed in native hemoglobin were found to undergo oxidation. There is evidence that these two sulfhydryl groups play a vital role in hemoglobin function. Riggs (3) showed that the addition of two PCMB molecules per molecule of hemoglobin resulted in a similar change in the oxygen equilibrium, as had been observed previously with aged hemoglobin solutions in vitro (32). Wyman presented evidence that the sigmoid oxygen equilibrium curve is the result of a widespread (tertiary) configurational change in the hemoglobin molecule on oxygenation (33). The X-ray diffraction studies of Perutz and associates (34), demonstrated that these sulfhydryl groups occupy key positions where the two different chains of the hemoglobin half molecule are contiguous; and it is possible that these sulfhydryl groups exert their influence on the oxygen equilibrium curve by altering the rearrangement of the chains that occur on oxygenation. Recently, Riggs and Wells (35) have shown that these two reactive sulfhydryl groups are on the $\beta$ chain of the hemoglobin, and have stressed the role of sulfhydryl groups in the Bohr effect; i.e., the influence of $\mathrm{pH}$ on the oxygen equilibrium curve (36).

With this evidence of the importance of these two sulfhydryl groups it is of considerable interest that, apart from the ferroheme groups, they bear the brunt of the initial oxidative assault on the hemoglobin molecule. Thus, when hemoglobin is titrated with increasing amounts of ferricyanide, after the four heme groups are oxidized two further groups are oxidized prior to precipitation. Amperometric titration of such ferricyanide-treated hemoglobin while still in solution shows that these two sulfhydryl groups are no longer available for mercury binding. Likewise, the total number of sulfhydryl groups measured in $8 \mathrm{M}$ urea has been reduced approximately from six to four. A similar sequence is observed when PCMB is added to the hemoglobin, 2 moles per mole of hemoglobin being bound prior to any precipitation. Furthermore, if these two sulfhydryl groups are blocked with $\mathrm{PCMB}$, phenylhydrazine 
precipitation of the hemoglobin is greatly potentiated. Phenylhydrazine likewise produces a diminution in native globin sulfhydryl groups although of a much lesser degree. The possibility of binding of phenylhydrazine to hemoglobin cannot be ruled out. Since phenylhydrazine alone lowers the galvanometer reading, such hemoglobin-bound phenylhydrazine might give a falsely high value of mercury-binding groups. As shown in Figure 12 , aging of hemoglobin at $37^{\circ} \mathrm{C}$ in vitro also leads to a decrease of titrable sulfhydryl groups in native globin. This decrease commences only after all of the glutathione has been oxidized and slightly anticipates and parallels hemoglobin precipitation.

\section{Significance of "fast-moving" components of he- moglobin}

Associated with oxidation of the first two sulfhydryls of globin is the occurrence in hemoglobin of changes in its oxygen dissociation curve (3) and, as shown here, in its electrophoretic mobility and its behavior on IRC 50 columns. However, it has not been shown that these changes necessarily represent identical alterations of the hemoglobin molecule. Riggs has found that the effects of PCMB and of aging on the oxygen dissociation curve of hemoglobin are reversible with GSH. However, such reversibility has not been observed with the changes in hemoglobin mobility on electrophoresis or on column chromatography. There is no difference in the number of titrable sulfhydryls between components $A_{I}$ and $A_{I I}$ isolated by column chromatography whether in fresh hemoglobin or in hemoglobin in which the usual number of two sulfhydryl groups has been diminished by ferricyanide treatment. It seems likely, therefore, that $A_{I}$, the fast-moving component, is not simply the main component of hemoglobin with two sulfhydryl groups oxidized but rather a further oxidized or denatured product thereof. While evidence presented here suggests that oxidation of globin sulfhydryls usually follows methemoglobin formation, it is entirely possible that they may be oxidized first under some conditions such as by oxygen at a high $\mathrm{pH}(3)$.

The electrophoretic and chromatographic changes produced by oxidative denaturation of hemoglobin are of importance in the interpretation of hemoglobin abnormalities with mobilities simi- lar to these fast-moving components. The reported (37) association of an unstable hemoglobin found in leukemia, with cresyl blue-staining inclusion bodies and increased fast-moving components on electrophoresis, is of especial interest. If this fast-moving component is indeed like those produced by oxidation (1) the likelihood of its being an acquired abnormality is increased. The instability of hemoglobin $\mathrm{H}$ (37), which consists entirely of $\beta$ chains (38), and which therefore should contain four, instead of two, readily reactive $-\mathrm{SH}$ groups, may well be attributed to this added lability to oxygen.

\section{The mechanism of hemoglobin precipitation}

Hemoglobin precipitates very slowly under oxygen. Oxidation or blockade of more than two sulfhydryl groups in the presence of oxygen results in an accelerated precipitation of hemoglobin; thus, when more than 6 moles of ferricyanide or 2 moles of PCMB per mole of hemoglobin was added under oxygen, precipitation proceeded within an hour rather than several days. As with hemoglobin precipitated during prolonged incubation, hemoglobin precipitated by ferricyanide and dissolved in $8 \mathrm{M}$ urea was found to have almost no titrable $\mathrm{SH}$ groups. The fact that, after the oxidation or blockade of two globin sulfhydryl groups, precipitation occurred only if oxygen was present suggests that interference with these two groups permitted subsequent auto-oxidation, probably irreversible, of other groups of the globin molecule with attendent denaturation. That this process occurs much more rapidly in the presence of redox intermediates such as phenylhydrazine is predictable in view of their known capacity to catalyze oxidation. Conversely, the marked effect of 2 or more moles of PCMB in rendering hemoglobin hypersusceptible to precipitation by phenylhydrazine and oxygen (Figure 11) indicates the protective function of globin sulfhydryls in terms of other oxidizable groups in globin, probably by maintaining the native molecular configuration.

The potentiating effect of a sulfhydryl inhibitor on hemoglobin precipitation by oxidant compounds is not to be confused with previous reports (4) of the ability of sulfhydryl inhibitors to convert normal red cells into "hypersusceptible" red cells in terms of Heinz body formation. The 


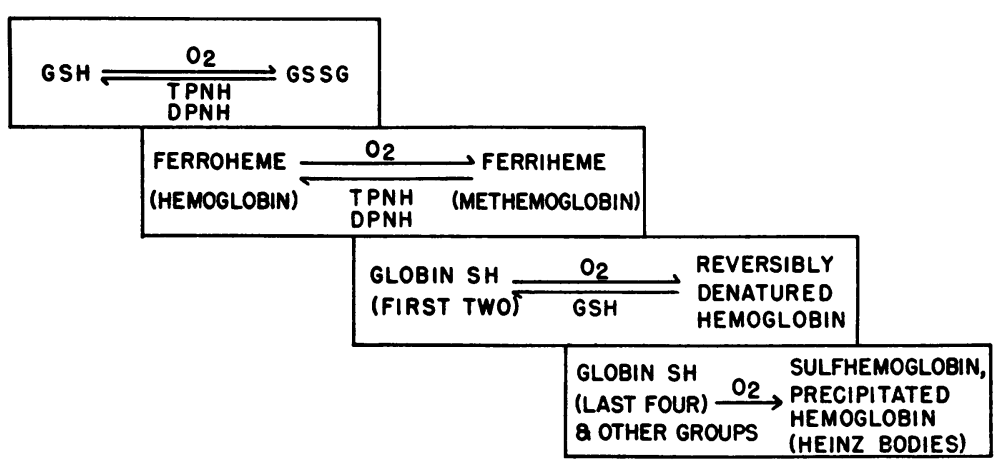

Fig. 14. Scheme of biochemical sequence during oxidative precipitaTION OF HEMOGLOBIN AND HEINZ BODY FORMATION.

latter effect was presumably due to injury to glycolytic enzymes (possibly glyceraldehyde-3-phosphate dehydrogenase), thereby inhibiting glycolysis.

Once precipitate has formed it cannot be redissolved by $\mathrm{SH}$ donors such as thioglycollate or mercaptoethanol. However, $8 \mathrm{M}$ urea is effective in dissolving the precipitated hemoglobin. The effect of urea suggests hydrogen bonding between the precipitated hemoglobin molecules. Thus, while oxidation of the sulfhydryl groups disrupts the globular structure of the hemoglobin molecule so that precipitation occurs, probably hydrogen bonds, and not disulfide bonds, hold together the disrupted polypeptide chains of the precipitated molecules.

Figure 14 summarizes the overlapping series of reactions that occur during oxidative hemolysis. Within a given cell the levels of the oxidized products accumulated will be determined by the relative activity of the reducing mechanisms involved in each step.

Protection of hemoglobin by GSH and the formation of "fast-moving" mixed disulfides

That glutathione provides a primary defense against intracellular oxidation is well demonstrated in hemoglobin solutions in vitro by its ability to retard methemoglobin formation and inhibit hemoglobin precipitation (Heinz body formation) either by oxygen alone or by oxygen with oxidant drugs. In the red cell, glutathione is supported in this role by active reducing systems, since addition of glucose to the suspending medium likewise slows oxidative changes. The observations of Mills (6) indicate that in the intact cell, glutathione peroxidase increases the efficiency with which GSH serves as a reductant. It cannot be stated with certainty that the crystalline hemoglobin employed in the present studies was free from this enzyme; if the hemoglobin was comparable in purity to that of Mills, it is unlikely that glutathione peroxidase activity was involved. An interesting observation that explains the tendency of glutathione-deficient red cells to develop many small, rather than a few large, Heinz bodies (39) is that glutathione, by slowing the rate of precipitation, results in fewer but larger granules of precipitated hemoglobin.

In defending hemoglobin against oxidation, GSH is to some extent bound to hemoglobin. Thus, when either $S^{35}$ or $C^{14}$-labeled GSH was mixed with both hemoglobin and phenylhydrazine, a portion of the GSH was precipitable with hemoglobin and traveled with hemoglobin during electrophoresis. That most of the labeled GSH could be detached with thioglycollic acid, but not by glycollic acid, confirms the supposition that this largely represents the formation of mixed disulfides during oxidation.

The appearance of labeled GSH in the fastmoving component of hemoglobin on electrophoresis suggests that the fast-moving hemoglobin of normal, senescent red cells may include hemoglobin-GSH disulfides and so represent another oxidative aspect of red cell aging in vivo (1). Indeed, there is unpublished evidence by Muller (40) that the fast-moving component of normal hemoglobin does contain glutathione. That the binding of GSH to hemoglobin by disulfide bonds during oxidation may account for the reported disappearance of GSH from red cells during hemolysis by primaquine and related phenylhydra- 
zine-like drugs $(4,5)$ seems reasonable. On the other hand, there is no reason to doubt that some of the GSH is oxidized beyond the reversible, disulfide state and so becomes unmeasurable. In support of this, it was found that after exposure to phenylhydrazine alone there was a gradual decrease in the total recoverable glutathione.

The role of thiols in protecting against injury by ionizing radiations frequently has been attributed to their ability to inactivate free radicals created by these radiations (41). Eldjarn and Pihl (42), on the other hand, demonstrated the propensity of protective thiols such as cysteamine to form mixed disulfides with various proteins, including hemoglobin, both in vitro and in animals. These authors suggested that thiols exert a protective action by reversibly binding the protein sulfhydryl groups and preventing further, irreversible injury. The similarity of the mode of injury by radiation to that of oxidant drugs, and the similar protective roles played by thiols in these two situations, make this hypothesis equally plausible with respect to oxidative hemolysis.

A previous paper (1) called attention to the similarities between the sequence of events leading to Heinz body formation in red cells and the changes culminating in cataract formation in the lens of the eye. The present report confirms this parallelism. With both hemoglobin and lens crystallin (43) the sequence is, 1) oxidation of glutathione, 2) oxidation of protein sulfhydryl groups, and 3) protein precipitation.

The fate of hemoglobin during oxidative damage as described in these studies is instructive in regard to possible mechanisms of cellular injury. Hemoglobin, being relatively rich in sulfhydryl groups and making up the bulk of the red cell protein, certainly is of chief importance in producing the morphological results of thiol oxidation, the Heinz bodies. However, it may be of no primary importance in determining red cell destruction. Glyceraldehyde-3-phosphate dehydrogenase, which is rich in sulfhydryl groups (44), and can be inhibited by - $\mathrm{SH}$ binding substances, may contain glutathione as a prosthetic group (45). This enzyme occupies a vital position in red cell glycolysis, and its inactivation may lead to an overwhelming of red cell reducing systems by oxidant drugs. Other sulfhydryl groups in other enzymes (46) and in the red cell mem- brane itself may well be involved in the cellular changes critical to the survival of the red cell in vivo (47). The observation here that sulfhydryl blockade by PCMB leads to a rapidly-ensuing spherocytosis and then hemolysis, occurring prior to the appearance of Heinz bodies, whereas spherocytosis and lysis are delayed manifestations of injury by phenylhydrazine and related compounds $(1,28)$, is consistent with the other evidence that such compounds must pass through an intermediate, hemecatalyzed step, prior to their critical action on cellular thiols, while the disruption of membrane integrity by $\mathrm{PCMB}$ is direct.

\section{SUM MARY}

During the oxidative injury of hemoglobin in solution or in red cells, thiol groups play a key role. Whether oxidation is spontaneous or accelerated by such electron-carrying compounds as phenylhydrazine, the following steps ensue.

1. Reduced glutathione (GSH) is oxidized to GSSG. In being oxidized a portion of the GSH becomes bound to hemoglobin by forming mixed disulfides with the globin sulfhydryl groups.

2. Hemoglobin is converted to methemoglobin as ferroheme becomes ferriheme.

3 . The two reactive sulfhydryl groups of native hemoglobin are oxidized.

4. Oxidation of these two thiol groups probably results in the loss of the normal configuration of the hemoglobin molecule with the following consequences: $a$ ) the oxygen equilibrium (dissociation curve) is altered; $b$ ) fast-moving components of hemoglobin, including mixed disulfides of GSH and hemoglobin, appear on electrophoresis or chromatography; $c$ ) other reactive groups of the globin molecule, including the remaining four sulfhydryl groups, become susceptible to oxidation.

5. Brown to green hemochromes form ("sulfhemoglobin").

6. Denatured hemoglobin molecules polymerize, probably by hydrogen bonding, and precipitate to form coccoid granules (Heinz bodies).

Glutathione buffers hemoglobin against oxidation and may protect globin sulfhydryls by formation of mixed disulfides. As a result, GSH slows the precipitation of hemoglobin so that fewer, larger Heinz bodies are formed. Probably GSH 
provides similar protection to other oxidatively labile constituents of the red cell such as the sulfhydryl groups of its enzymes and of its membrane. Presumably, injury to these latter components accounts for the actual hemolysis in vivo and for the spherocytosis observed in vitro.

\section{ADDENDUM}

Since the publication of the first paper in this series (1) it has come to our attention that E. L. Nelson had described the formation of spherical particles under certain conditions in water lysates of red cells (Nelson, E. L. The development in vitro of particles from cytoplasm. I. Observations on particle development in bacteriologic media. II. Particles from hemoglobin and desoxyribonucleic acid. J. exp. Med. 1958, 107, 769). Of particular interest is the author's finding that at a low $\mathrm{pH}$, particle formation could be induced in red cell lysates by the addition of desoxyribonucleic acid (DNA). Such particles contained a mixture of hemoglobin and DNA, and were capable during their formation of trapping and incorporating extraneous proteins and polysaccharides, which may explain the atypical staining characteristics of the inclusions of congenital inclusion body anemias.

\section{REFERENCES}

1. Jandl, J. H., Engle, L. K., and Allen, D. W. Oxidative hemolysis and precipitation of hemoglobin. I. Heinz body anemias as an acceleration of red cell aging. J. clin. Invest. 1960, 39, 1818.

2. Fegler, G. Relationship between reduced glutathione content and spontaneous haemolysis in shed blood. Nature (Lond.) 1952, 170, 624.

3. Riggs, A. F. Sulfhydryl groups and the interaction between the hemes in hemoglobin. J. gen. Physiol. 1952, 36, 1.

4. Beutler, E., Dern, R. J., Flanagan, C. L., and Alving, A. S. The hemolytic effect of primaquine. VII. Biochemical studies of drug-sensitive erythroyctes. J. Lab. clin. Med. 1955, 45, 286.

5. Beutler, E., Robson, M., and Buttenwieser, E. The mechanism of glutathione destruction and protection in drug-sensitive and non-sensitive erythrocytes. In vitro studies. J. clin. Invest. 1957, 36, 617.

6. Mills, G. C. The purification and properties of glutathione peroxidase of erythrocytes. J. biol. Chem. 1959, 234, 502.

7. Carson, P. E., Flanagan, C. L., Ickes, C. E., and Alving, A. S. Enzymatic deficiency in primaquinesensitive erythrocytes. Science 1956, 124, 484.

8. Rall, T. W., and Lehninger, A. L. Glutathione reductase of animal tissues. J. biol. Chem. 1952, 194, 119.

9. Francoeur, M., and Denstedt, O. F. Metabolism of mammalian erythrocytes. VII. The glutathione reductase of the mammalian erythrocyte. Canad. J. Biochem. 1954, 32, 663.

10. Drabkin, D. L. A simplified technique for a large scale crystallization of human oxyhemoglobin. Isomorphous transformations of hemoglobin and myoglobin in the crystalline state. Arch. Biochem. 1949, 21, 224.

11. Cecil, R., and McPhee, J. R. The sulfur chemistry of proteins. Advanc. Protein Chem. 1959, 14, 255.

12. Evelyn, K. A., and Malloy, H. T. Microdetermination of oxyhemoglobin, methemoglobin, and sulfhemoglobin in a single sample of blood. J. biol. Chem. 1938, 126, 655.

13. Allen, D. W., Schroeder, W. A., and Balog, J. Observations on the chromatographic heterogeneity of normal adult and fetal human hemoglobin: A study of the effects of crystallization and chromatography on the heterogeneity and isoleucine content. J. Amer. chem. Soc. 1958, 80, 1628.

14. Grunert, R. R., and Phillips, P. H. A modification of the nitroprusside method of analysis for glutathione. Arch. Biochem. 1951, 30, 217.

15. Beutler, E. The glutathione instability of drugsensitive red cells. A new method for the in vitro detection of drug sensitivity. J. Lab. clin. Med. 1957, 49, 84.

16. Dohan, J. S., and Woodward, G. E. Electrolytic reduction and determination of oxidized glutathione. J. biol. Chem. 1939, 129, 393.

17. Kolthoff, I. M., Stricks, W., and Morren, L. Amperometric mercurimetric titration of sulfhydryl groups in biologically important substances at the rotated platinum wire electrode as indicator electrode. Analyt. Chem. 1954, 26, 366.

19. Sheets, R. F., Hamilton, H. E., and DeGowin, E. L. Hemolysis of human erythrocytes by a sulfhydryl inhibitor, p-chloromercuribenzoic acid. Proc. Soc. exp. Biol. (N. Y.) 1956, 91, 423.

19. Ingram, V. M. Sulphydryl groups in haemoglobins. Biochem. J. 1955, 59, 653.

20. Allison, A. C., and Cecil, R. The thiol groups of normal adult human haemoglobin. Biochem. J. 1958, 69, 27.

21. Anderson, L., and Plaut, G. W. E. Table of oxidation-reduction potentials in Respiratory Enzymes, H. A. Lardy, Ed. Minneapolis, Burgess, 1949, p. 71.

22. Lemberg, R., and Legge, J. W. Hematin Compounds and Bile Pigments; Their Constitution, Metabolism, and Function. New York Interscience Publishers, 1949.

23. Kiese, M. Die Reduktion des Hämiglobins. Biochem. Z. 1944, 316, 264.

24. Dimant, E., Landsberg, E., and London, I. M. The metabolic behavior of reduced glutathione in human and avian erythrocytes. J. biol. Chem. 1955, 213, 769.

25. Scott, E. M., and Hoskins, D. D. Hereditary methemoglobinemia in Alaskan Eskimos and Indians. Blood 1958, 13, 795. 
26. Beaven, G. H., and White, J. C. Oxidation of phenylhydrazines in the presence of oxyhaemoglobin and the origin of Heinz bodies in erythrocytes. Nature (Lond.) 1954, 173, 389.

27. Oberst, F. W., and Woods, E. B. Studies in glutathione. II. Relation between reduced and oxidized glutathione and the oxygen content and capacity of blood. J. biol. Chem. 1935, 111, 1 .

28. Emerson, C. P., Ham, T. H., and Castle, W. B. Hemolytic action of certain organic oxidants derived from sulfanilamide, phenylhydrazine and hydroquinone (abstract). J. clin. Invest. 1941, 20, 451.

29. Bodansky, O. Methemoglobinemia and methemoglobin-producing compounds. Pharmacol. Rev. 1951, 3, 144.

30. Morrison, D. B., and Williams, E. F., Jr. Methemoglobin reduction by glutathione or cysteine. Science 1938, 87, 15.

31. Ingram, V. M. The sulphydryl groups of sickle-cell haemoglobin. Biochem. J. 1957, 65, 760.

32. Allen, D. W., Guthe, K. F., and Wyman, J., Jr. Further studies on the oxygen equilibrium of hemoglobin. J. biol. Chem. 1950, 187, 393.

33. Wyman, J., Jr., and Allen, D. W. The problem of heme interactions in hemoglobin and the basis of the Bohr effect. J. Polym. Sci. 1951, 7, 499.

34. Perutz, M. F., Rossman, M. G., Cullis, A. F., Muirhead, H., Will, G., and North, A. C. T. Structure of haemoglobin. Nature (Lond.) 1960, 185, 416.

35. Riggs, A., and Wells, M. The identification of the oxygenation-linked acid groups with the $\beta$-chain of human hemoglobin. Fed. Proc. 1960, 19, 78.

36. Riggs, A. The nature and significance of the Bohr effect in mammalian hemoglobins. J. gen. Physiol. 1960, 43, 737.
37. White, J. C., Ellis, M., Coleman, P. N., Beaven, G. H., Gratzer, W. B., Shooter, E. M., and Skinner, E. R. An unstable haemoglobin associated with some cases of leukaemia. Brit. J. Haemat. 1960, 6, 171.

38. Jones, R. T., Schroeder, W. A., Balog, J. E., and Vinograd, J. R. Gross structure of hemoglobin H. J. Amer. chem. Soc. 1959, 81, 3161.

39. Beutler, E., Dern, R. J., and Alving, A. S. The hemolytic effect of primaquine. VI. An in vitro test for sensitivity of erythrocytes to primaquine. J. Lab. clin. Med. 1955, 45, 40.

40. Muller, C. J. Personal communication.

41. Patt, H. M. Protective mechanisms in ionizing radiation injury. Physiol. Rev. 1953, 33, 35.

42. Eldjarn, L., and Pihl, A. On the mode of action of $x$-ray protective agents. I. The fixation in vivo of cystamine and cysteamine to proteins. J. biol. Chem. 1956, 223, 341.

43. Dische, Z., and Zil, H. Studies on the oxidation of cysteine to cystine in lens proteins during cataract formation. Amer. J. Ophthal. 1951, 34, no. 5 (Part 2), 104.

44. Koeppe, O. J., Boyer, P. D., and Stulberg, M. P. On the occurrence, equilibria, and site of acylenzyme formation of glyceraldehyde-3-phosphate dehydrogenase. J. biol. Chem. 1956, 219, 569.

45. Krimsky, I., and Racker, E. Glutathione, a prosthetic group of glyceraldehyde-3-phosphate dehydrogenase. J. biol. Chem. 1952, 198, 721.

46. Rapoport, S., and Scheuch, D. Glutathione stability and pyrophosphatase activity in reticulocytes; direct evidence for the importance of glutathione for the enzyme status in intact cells. Nature (Lond.) 1960, 186, 967.

47. London, I. M. Metabolism of the mammalian erythrocyte. Bull. N. Y. Acad. Med. 1960, 36, 79.

\section{ERRATUM}

In the paper of $\mathrm{H}$. Bennhold and $\mathrm{E}$. Kallee "Comparative studies on the half-life of $\mathrm{I}^{131}$-labeled albumins and nonradioactive human serum albumin in a case of analbuminemia," J. clin. Invest. 1959, 38, 863, "CuSO 4 " in line 15 from the bottom of the right column of p. 864 should read " $\mathrm{CdSO}_{4}$ "; i.e., cadmium sulfate instead of copper sulfate. 